\title{
Fatigue life of machined components
}

\author{
A. Pramanik ${ }^{1 *}$, A.R. Dixit², S. Chattopadhyaya ${ }^{2}$, M. S. Uddin ${ }^{3}$, Yu Dong ${ }^{1}$, A. K. Basak ${ }^{4}$, G. Littlefair ${ }^{5}$ \\ ${ }^{1}$ Department of Mechanical Engineering, Curtin University, Bentley, WA 6102, Australia \\ ${ }^{2}$ Department of Mechanical Engineering, Indian School of Mines, Dhanbad-826004, India. \\ ${ }^{3}$ School of Engineering, University of South Australia, Mawson Lakes, SA 5095, Australia \\ ${ }^{4}$ Adelaide Microscopy, The University of Adelaide, Adelaide, SA, Australia \\ ${ }^{5}$ School of Engineering, Deakin University, Waurn Ponds, VIC, Australia
}

\section{*Corresponding author}

Phone: +61 89266 7981, Fax: +61 89266 2681, Email: alokesh.pramanik@curtin.edu.au

\begin{abstract}
The correlation between machining process and fatigue strength of machined components clearly exists. However, a complete picture of the knowledge on this is not readily available for practical applications. This study addresses this issue by investigating the consequence of machining methods on fatigue life of commonly used materials such as titanium alloys, steel, aluminium alloys and nickel alloys from previous literatures. Effects of turning, milling, grinding and different non-conventional machining processes on fatigue strength of above-mentioned materials have been investigated in details with correlated information. It is found that the effect of materials is not significant except steel in which phase change causes volume expansion, resulting in compressive/tensile residual stresses based on the amounts of white layers. It is very complex to identify the influence of surface roughness on the fatigue strength of machined components in the presence of residual stresses. The polishing process improves the surface roughness, but removes the surface layers that contain compressive residual stresses to decrease the fatigue strength of polished specimens. The compressive and tensile residual stresses improve and reduce fatigue strength, respectively. Grinding process induces tensile residual stresses on the machined surfaces due to the generation of high temperature. On the other hand, milling and turning processes induce compressive residual stresses. High temperature non-conventional machining generates a network of micro-cracks on the surfaces in addition to tensile residual stresses
\end{abstract}


to subsequently reduce fatigue strength of machined components. Embedded grits of abrasive water jet machining degrade the fatigue performance of components machined by this method.

Key words: Traditional machining, non-traditional machining, fatigue strength, surface roughness, residual stress, phase change.

\section{Introduction}

Materials under a fluctuating stress fail at much lower stress level than those under the static fracture stress. This fact is particularly important when designing aerospace, automobile and biomedical components (Bentley, Mantle et al. 1999, Zhang, Kiat et al. 2009, Pramanik, Zhang et al. 2010). It is well known that the cracks due to fatigue usually start from free surfaces as it undergoes the maximum load and environmental effects (Zahavi, Torbilo et al. 1996, Javidi, Rieger et al. 2008). The fatigue performance of a component depends on the topography/integrity of the machined surfaces produced by different machining procedures. Thus the surfaces generated from diverse machining processes show a wide range of fatigue behaviours (Zlatin and Field 1973). Therefore, machining induced residual stresses, microstructures, microhardness and notch-like surface irregularities affect the fatigue strength significantly (Novovic, Dewes et al. 2004, Dieter 2015). The high cycle fatigue strength is the main mechanical property that is affected by machining, in which rougher surfaces inspire the start of fatigue crack, especially for notch-sensitive materials (Koster and Field 2001). The surface microstructure includes phases, plastic deformation, tears, voids, pits, burrs, cracks and hardness. The machined surfaces are work-hardened severely with micro cracks. This change in the surfaces depends on the harshness of the parameters used during a machining process (Mantle and Aspinwall 1997). The tensile residual stresses on the machined surfaces degrade the fatigue life (Taylor and Clancy 1991, Javidi, Rieger et al. 2008).

Cast or wrought processes produce near net shape, but machining processes generate final details of products. Appropriate precautions must be taken during the machining of components to ensure expected roughness and integrity of the machined surfaces/subsurfaces as those affect the service life duration significantly. There are some studies on the fatigue behaviour of machined components, which shows that a variety of materials and machining processes have different effects on fatigue strength. A clear understanding of these effects is not yet available though it is imperatively required to utilise machined components more efficiently. This paper investigates the contributions of machining parameters on the fatigue strength of various materials such as titanium alloys, steels, aluminium alloys and nickel alloys in the previous work. This review is anticipated to bridge all the understandings 
obtained by various researchers and, scientifically and systematically analyse those to give a complete understanding of fatigue behaviour of machined components.

\section{Titanium alloys}

Titanium alloys are mainly used in high-tech applications because of their excellent properties, but with high processing cost (Pramanik and Littlefair 2014, Pramanik and Littlefair 2015). Therefore much research has been performed on this metal alloy material. The latest work has been dedicated to experimental investigations of the inherent basis of inconsistency in fatigue strengths of machined titanium alloys. A significant scatter in fatigue data is evident specifically due to metallurgical aspects (Jha, Szczepanski et al. 2012).

\subsection{Effect of turning}

The S-N results of $\mathrm{Ti}-45 \mathrm{Al}-2 \mathrm{Nb}-2 \mathrm{Mn}-0.8 \% \mathrm{TiB}_{2}$ turned at different feeds and speed are given in Fig. 1. The scatter of the results for turned specimens is quite high at all stress levels, which becomes lower for polished specimens at higher stress levels. The fatigue life of turned specimens diminishes at higher stresses owing to corresponding cracks initiation. No clear trends of fatigue lives of specimens machined at speeds of 10 and $25 \mathrm{~m} / \mathrm{min}$, feeds of 0.1 and $0.05 \mathrm{~mm} / \mathrm{rev}$ with the depth of cut of $0.3 \mathrm{~mm}$ are noted (Mantle and Aspinwall 1997).

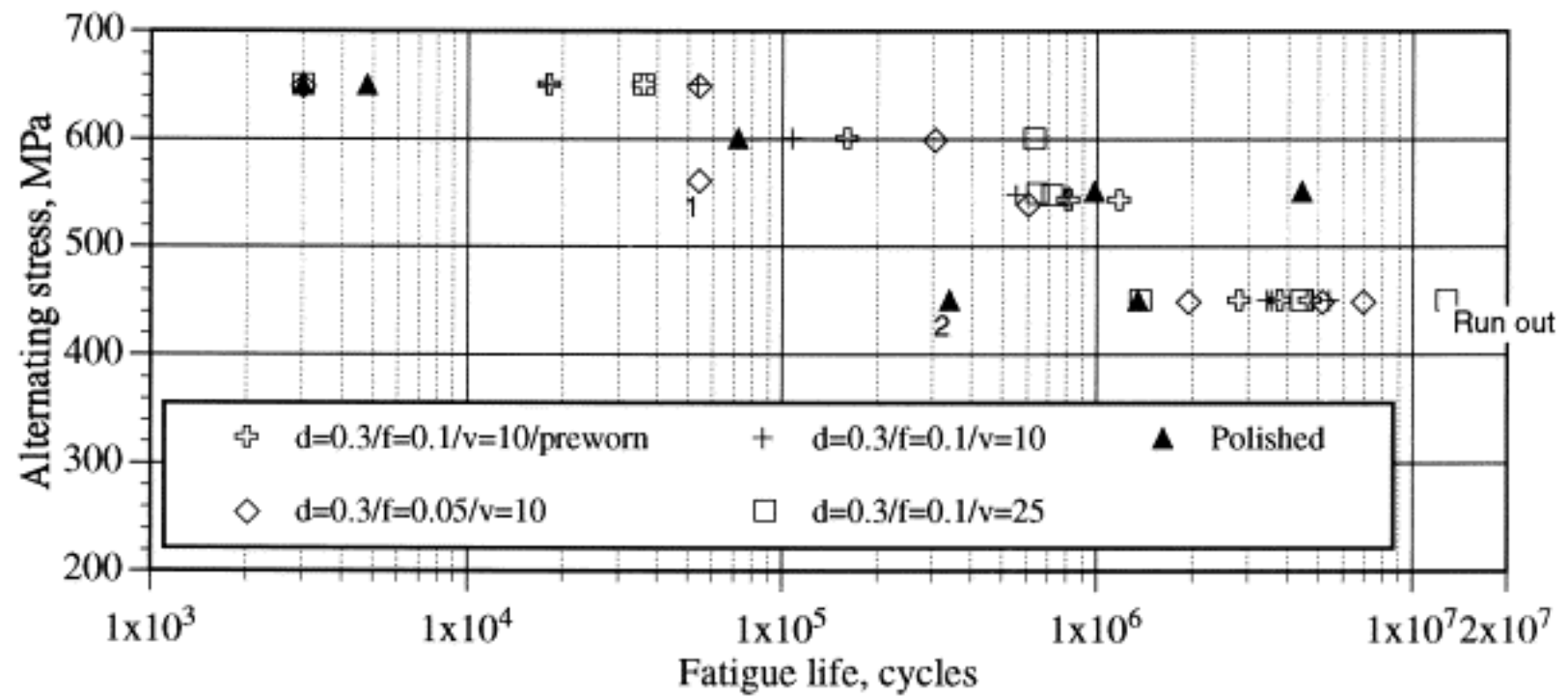

Fig. 1. Rotating bending fatigue life of Ti-45Al-2Nb-2Mn-0.8\% $\mathrm{TiB}_{2}$ (Mantle and Aspinwall 1997). According to Mantle and Aspinwall (Mantle and Aspinwall 1997), turned gamma alloys contain high compressive residual stresses in machined surfaces (around $600 \mathrm{MPa}$ ). The stresses in the longitudinal 
direction were smaller than those in the transverse direction. The surfaces generated from grinding also contain compressive residual stresses (Zhang 1995). It is natural that the work pieces machined by worn tools would have higher compressive residual stresses on the surfaces (Xie, Bayoumi et al. 1989), which reduces the peak tensile stress and shows longer fatigue lives at the given stress when compared to the specimens machined at $10 \mathrm{~m} / \mathrm{min}$ in speed, $0.1 \mathrm{~mm} / \mathrm{rev}$ in feed and $0.3 \mathrm{~mm}$ in depth of cut. However, Fig. 1 does not support the above. The specimens polished at 450, 600 and $650 \mathrm{MPa}$ have lower fatigue life as opposed to turned specimens, as shown in Fig. 1. This indicates that the fatigue life of polished specimens is shorter due to little/no compressive residual stresses in the machined surfaces though polished specimens were free from cracks. Unfortunately, specimens polished at $550 \mathrm{MPa}$ possess the highest average fatigue life. An approximate endurance limit of $350 \mathrm{MPa}$ for all the specimens was calculated based on Fig. 1. A significant difference in endurance limit for different machining parameters was not manifested. The similar trend was noted for Inconel 718, which got endurance limits of $420 \mathrm{MPa}$ when gentle ground surfaces were compared with gentle and harsh turned surfaces (Field, Kahles et al. 1972).

\subsection{Effect of grinding}

Fig. 2 shows flat $\mathrm{S}-\mathrm{N}$ curves for high cycle four-point bending of $\mathrm{Ti}-45 \mathrm{Al}-2 \mathrm{Nb}-2 \mathrm{Mn}-0.8 \% \mathrm{TiB}_{2}$ processed at different conditions. The similar results are noted for electrical discharge machined (Trail and Bowen 1995) and turned specimens (Mantle and Aspinwall 1997). The fatigue strengths of fineground workpieces are inferior to those of polished and rough-ground counterparts. It seems that tensile residual stresses take place in the machined surfaces, which might be due to too much heating from the grinding process, as previously mentioned by Koster et al. (Koster and Field 1973) when grinding an $\alpha / \beta$ titanium alloy. Characteristically, rough grinding generates higher tensile residual stresses than that of finish-grinding, thus leading to higher fatigue life of a finish ground (Bentley, Mantle et al. 1999). Metallographic sections show no microstructural differences between polished and fine-ground surfaces. Distorted lamellae were seen in the rough-ground and high speed milled surfaces.

\subsection{Effect of milling}

Distorted lamellae were also seen in the high speed milled surfaces where the depth of the distorted lamellae was up to $20 \mu \mathrm{m}$. Cracks were observed in single-point-turned specimens (Mantle and Aspinwall 1997) and in the samples after high speed milling with worn tools, depicted in Fig. 3. High speed milled specimens show significantly higher fatigue strength due to the increase of subsurface microhardness and deformation. The workpieces machined at the high speed have much harder and plastically deformed subsurfaces compared to ground and polished surfaces. Such plastic deformation 
associated with the ploughing by the cutting tool, causes compressive residual stresses. The cracks in the machined surface generated from high speed milling (HSM) by worn tool explain lower run-out values (Bentley, Mantle et al. 1999).

In general, trans-lamellar fracture and inter-lamellar failure are the predominant micro-mechanisms of failure (Trail and Bowen 1995). The deformation of the surfaces during high-speed milling may limit the crack growth from the lamellae borders, which restricts failure among lamellar and increases the fatigue strength of the components (Bentley, Mantle et al. 1999). Roughness of the machined surfaces significantly affects the fatigue strength of components. The surface waves act as stress concentrators and initiates cracks (Taylor and Clancy 1991). However, the increase of fatigue strength was not obvious with the increase in surface finish due to the presence of residual stresses in the machined surfaces (Bentley, Mantle et al. 1999).

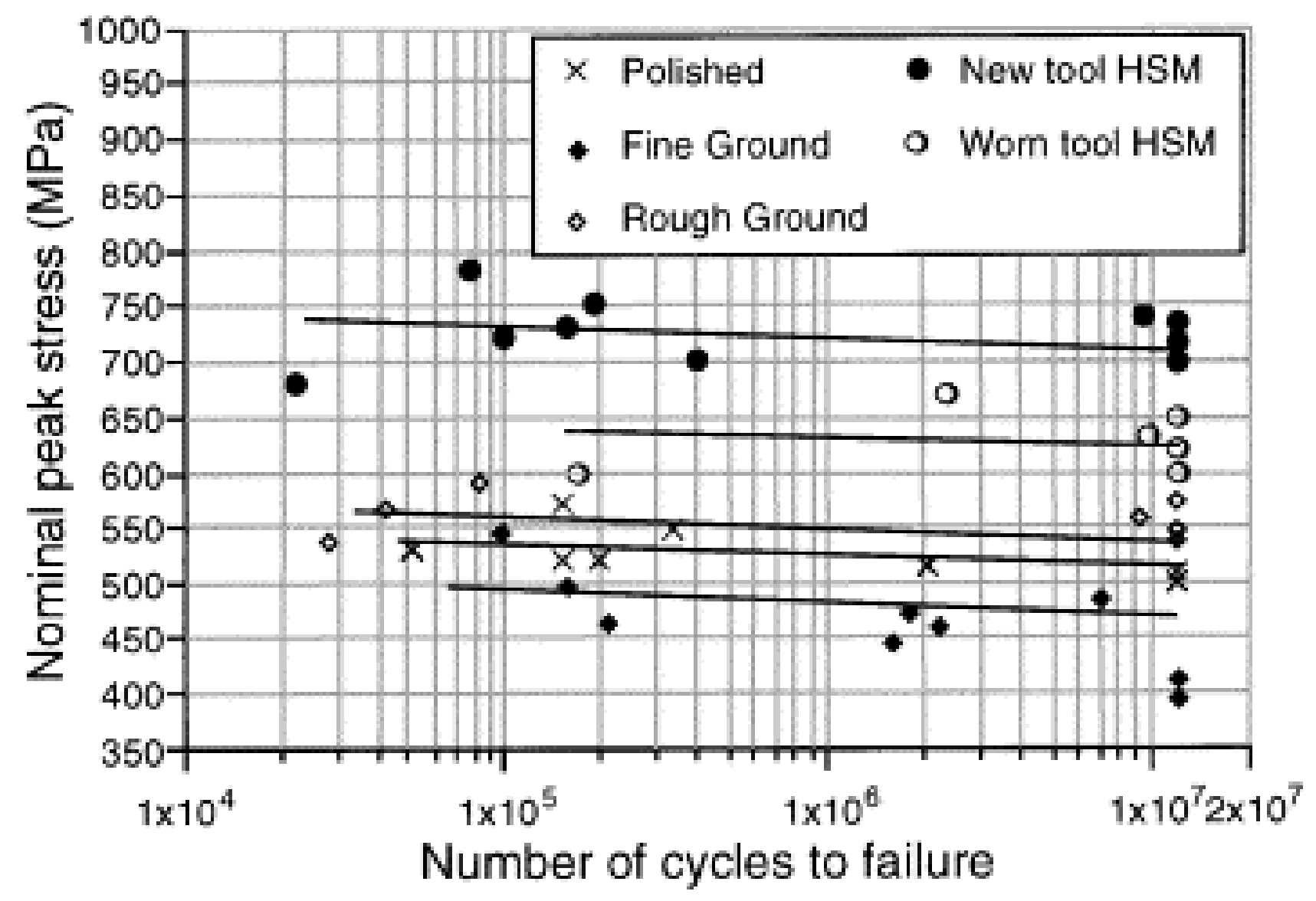

Fig. 2. High cycle, four-point bending, S-N curves for machined and polished Ti-45Al-2Nb-2Mn0.8\% $\mathrm{TiB}_{2}$ surfaces (Bentley, Mantle et al. 1999). 


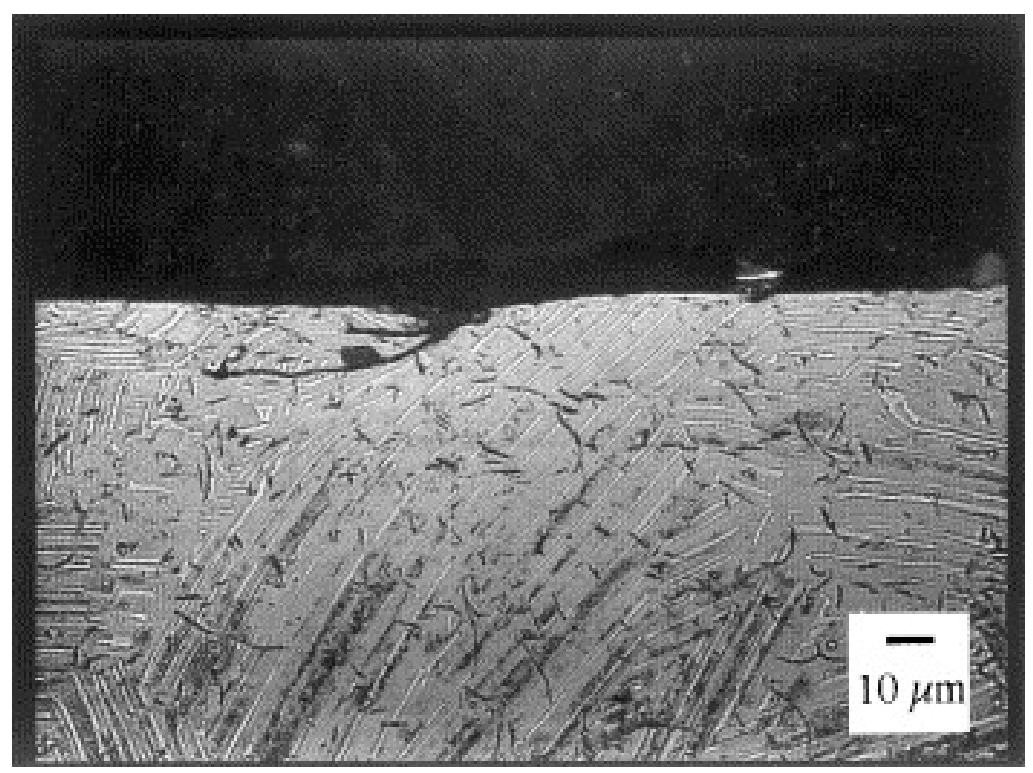

Fig. 3. Cracks in the machined surfaces produced by HSM with a worn tool (Bentley, Mantle et al. 1999).

All titanium alloy specimens experienced brittle fracture, as shown in Fig. 4 (Bentley, Mantle et al. 1999), which displays inter-lamellar, intra-lamellar and trans-lamellar fracture. Inter-lamellar and intralamellar transmission yields fracture surfaces parallel to lamellar boundaries and trans-lamellar spreads nearly in the normal direction to the lamellar boundaries. Fracture commencement locations on the surface are difficult to assess. It appears that untimely fracture at points 1 and 2 in Fig. 1 might be associated with the surface imperfection or favourable alignment of neighbouring groups to facilitate interfacial fractures.

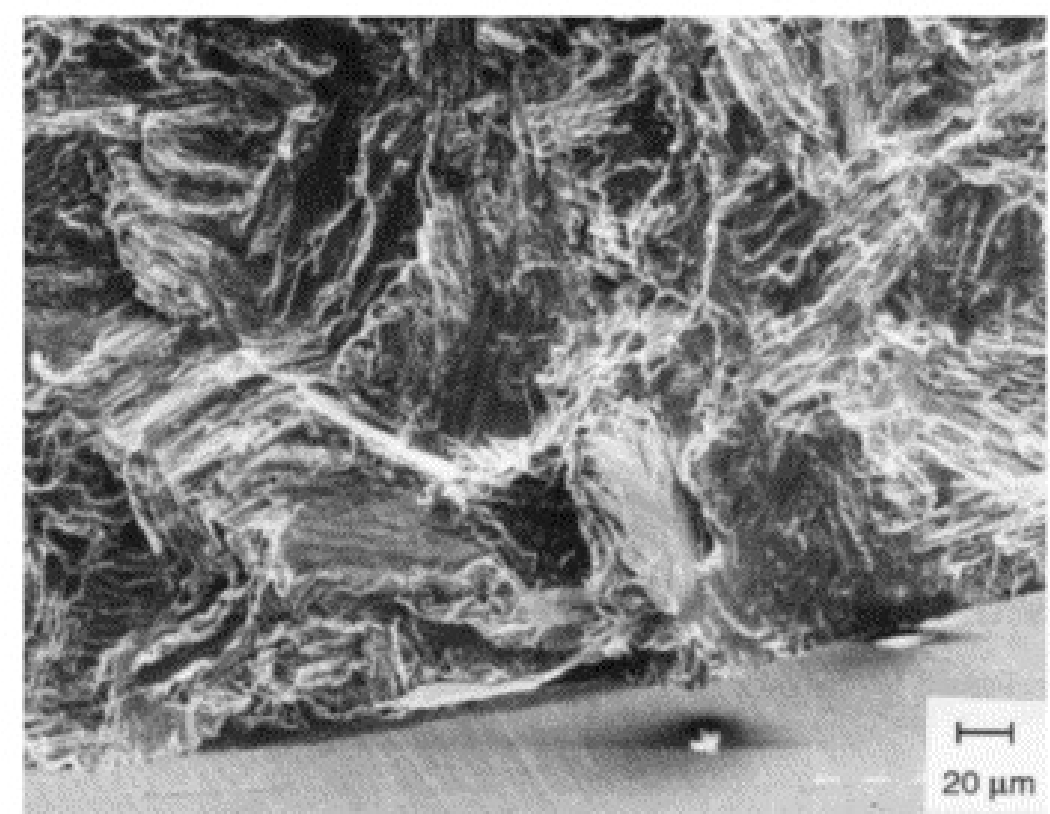

Fig. 4. Ti-45Al-2Nb-2Mn-0.8\%TiB 2 fatigue fracture surfaces (Mantle and Aspinwall 1997) 


\subsection{Effect of electrical discharge machining (EDM)}

EDM process of Ti-6Al-4V produces lower surface roughness $\left(R_{\mathrm{a}} \sim 0.2 \mu \mathrm{m}\right)$ and fatigue limits (200 MPa) (Klocke, Welling et al. 2011). However, the aggressive EDM processing parameters on bimodal, annealed Ti-6Al-4V results in higher surface roughness $\left(R_{\mathrm{a}}=11.6 \mu \mathrm{m}\right.$ and $\left.R_{\max }=78 \mu \mathrm{m}\right)$ (Janeček, Nový et al. 2011). Rotating-beam tests demonstrate severely reduced fatigue strength due to the EDM process. The fatigue limit is less than $100 \mathrm{MPa}$ for the specimens after EDM while that of electro-polished specimens produced a fatigue limit of approximately $550 \mathrm{MPa}$. This degradation was attributed to both a high population of micro-cracks and tensile residual stresses on the specimen surfaces produced by EDM. The electro-polished specimens were reported to have zero roughness. The endurance limit of bi-modal, EDM-processed specimens can be increased significantly by stress relieving at $500^{\circ} \mathrm{C}$ (Mower 2014). Fatigue behaviour of EDM processed Ti-6Al$4 \mathrm{~V}$ alloy consists of three types of microstructures namely, equi-axed, bimodal and coarse lamellar, illustrated in Fig. 5. The S-N curves are for all three microstructures of titanium alloys after EDM is compared with electro-polishing. The fatigue behaviour of equi-axed and bi-modal microstructures after electro-polishing depends on the prior ageing and the size of grains (Stráský, Janeček et al. 2011). The fatigue endurance limit of electro-polished equi-axed and bi-modal microstructures is equal. The fatigue strength of coarse lamellar structure is much poorer than that of equi-axed or bi-modal structures (Mueller, Rack et al. 2007). Fig. 5 (b) compares the fatigue performances of different microstructures processed by EDM, which shows a significant decrease in the fatigue performance of all microstructures after EDM. This is due to the notch sensitivity of titanium alloys, perhaps brittle surface layers and micro-cracks generated from the EDM. It is also shown that the effect of EDM processed microstructure on the high cycle fatigue strength is small. The commencement of cracks in rotating bending is generally controlled by the quality and topography of machined surfaces (Leinenbach and Eifler 2006). Better fatigue performance at high stress amplitudes is noted for the coarse lamellar structure due to slower crack propagation, which is caused by the deviations of the crack tip from the average transmission plane. The longer high cycle fatigue life of bi-modal structure at low stresses proposes a longer micro-crack spreading phase (Janeček, Nový et al. 2011). 

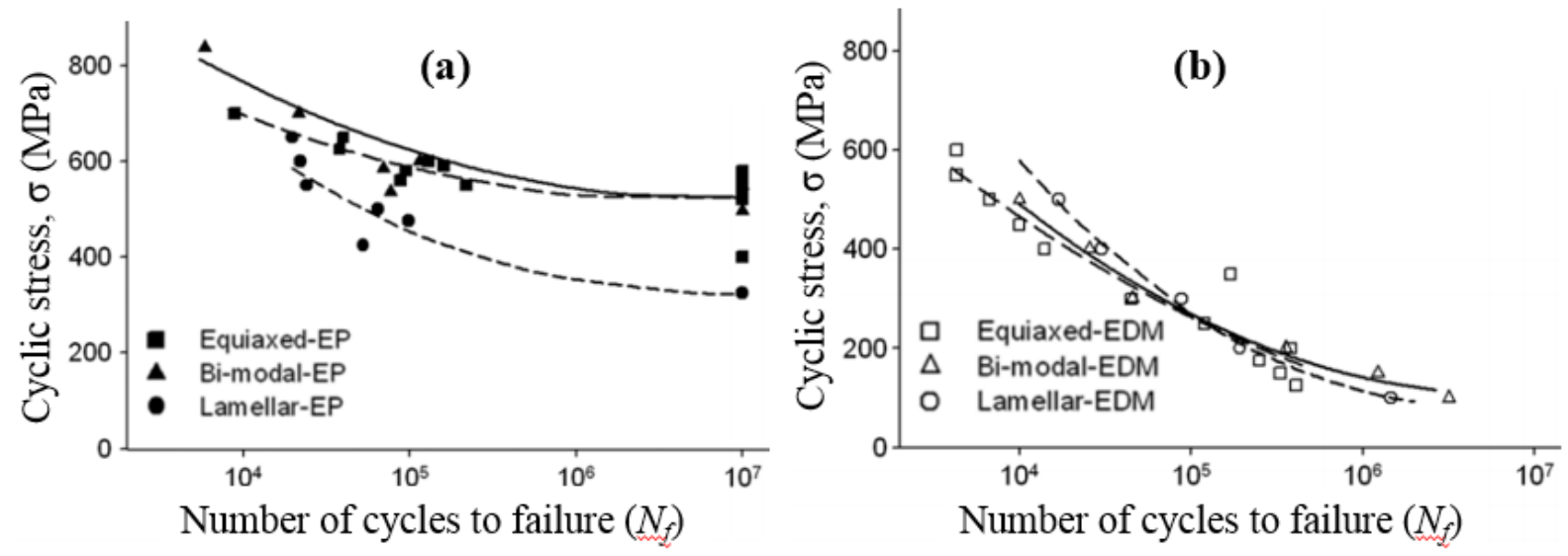

Fig. 5 S-N curves of Ti-6Al-4V alloy with different microstructures after (a) electro-polishing and (b) EDM (Stráský, Janeček et al. 2011).

\subsection{Comparison of different non-traditional machining processes}

Fig. 6 shows the S-N curves for Ti-6Al-4V samples manufactured by different processes. The curves are comparatively straight where the number of cycles to failure varied significantly with similar amounts of stresses. The specimens manufactured by turning has highest run-out strength of $475 \mathrm{MPa}$. Electro-chemical machined (ECM) samples had a marginally lower run-out strength of $440 \mathrm{MPa}$, while the electro-discharge textured sample by low energy parameters (EDT-L) and electro-discharge textured samples by high energy parameters (EDT-H) had considerably lower values of 357 and 225 MPa, respectively (Sharman, Aspinwall et al. 2001).

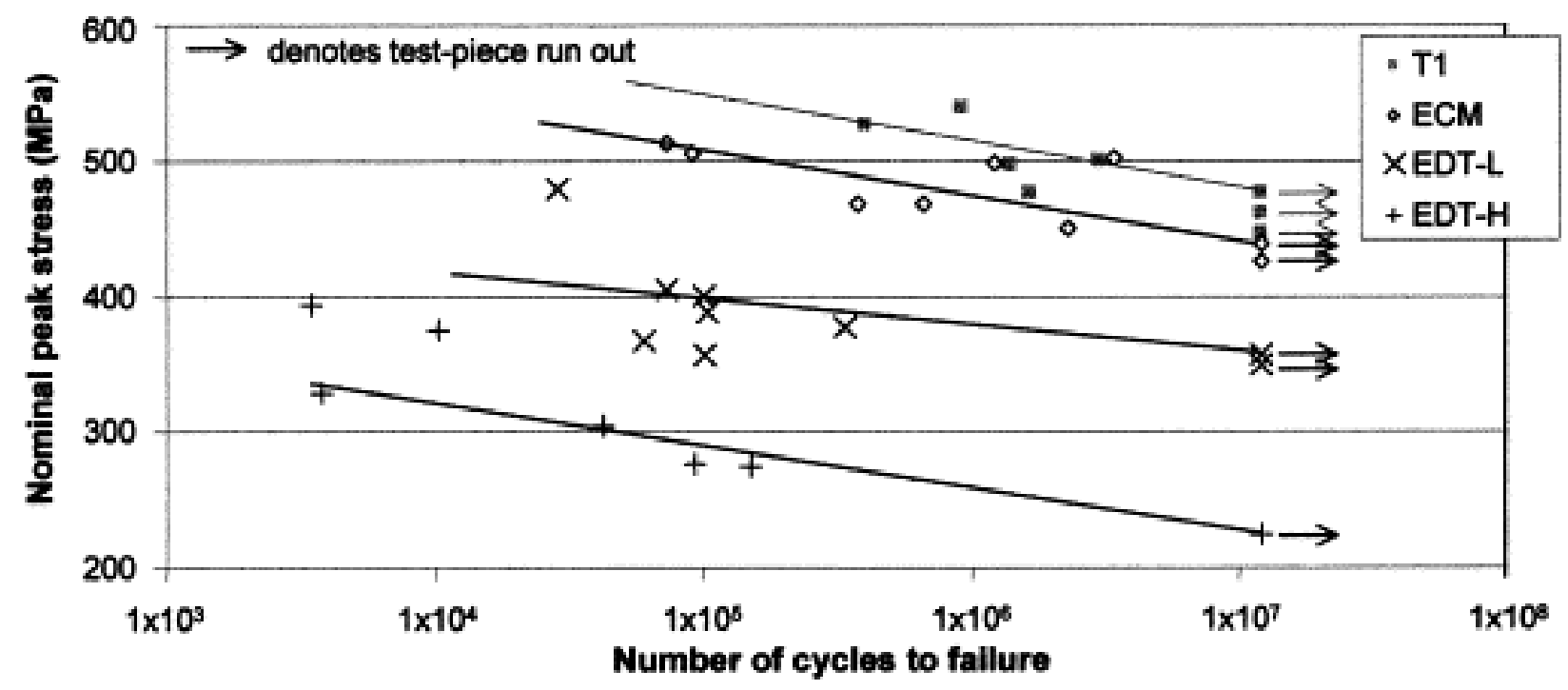

Fig. 6. S-N curves for turned, ECM and EDT specimens (Sharman, Aspinwall et al. 2001).

The existence of cracks that propagate into the bulk of the material, is the main cause of low fatigue strength of specimens produced by the EDT, as shown in Fig. 7 (a). Very high temperature is produced in the EDT process $\left(\sim 12,000^{\circ} \mathrm{C}\right)$, which melts the metal during machining. A molten pool of metal 
resolidifies at the workpiece surface after machining. This solidification process is very rapid, which generates tensile residual stresses and micro-cracks on the machined surfaces. The cracks were not constrained to the recast white layers, but also prolonged into the material beneath (Sharman, Aspinwall et al. 2001). These cracks tended to follow lamellae and colony boundaries without much resistance to the spread of fatigue cracks (Campbell, Rao et al. 1997). Comparatively rough surfaces $(\mathrm{Ra}=1.43 \mu \mathrm{m})$ of ECM specimens were generated by a discerning etching of distinct lamellae within individual colony, as shown in Fig. 7 (b). Apparently there were no cracks on the surfaces generated by ECM. However, the selectively etched lamellae act as stress concentration points and the adherence of distinct lamellae offers the minor resistance to the crack commencement. On the other hand, there are small shallow cracks ( $<5 \mu \mathrm{m}$ deep) in the turned specimens, as exhibited in Fig. 7 (c), and these cracks did not spread during fatigue tests. Crack origination on the specimens produced by turning occurred due to the failure of inter-lamellar plate within lamellae colonies that were oriented at a certain angle to the applied load. In this case, the crack propagated at surfaces and internal sites. The longer fatigue life was demonstrated by the turned specimens as it required more cycles to propagate cracks through the compressive residual stress layers (Sharman, Aspinwall et al. 2001).
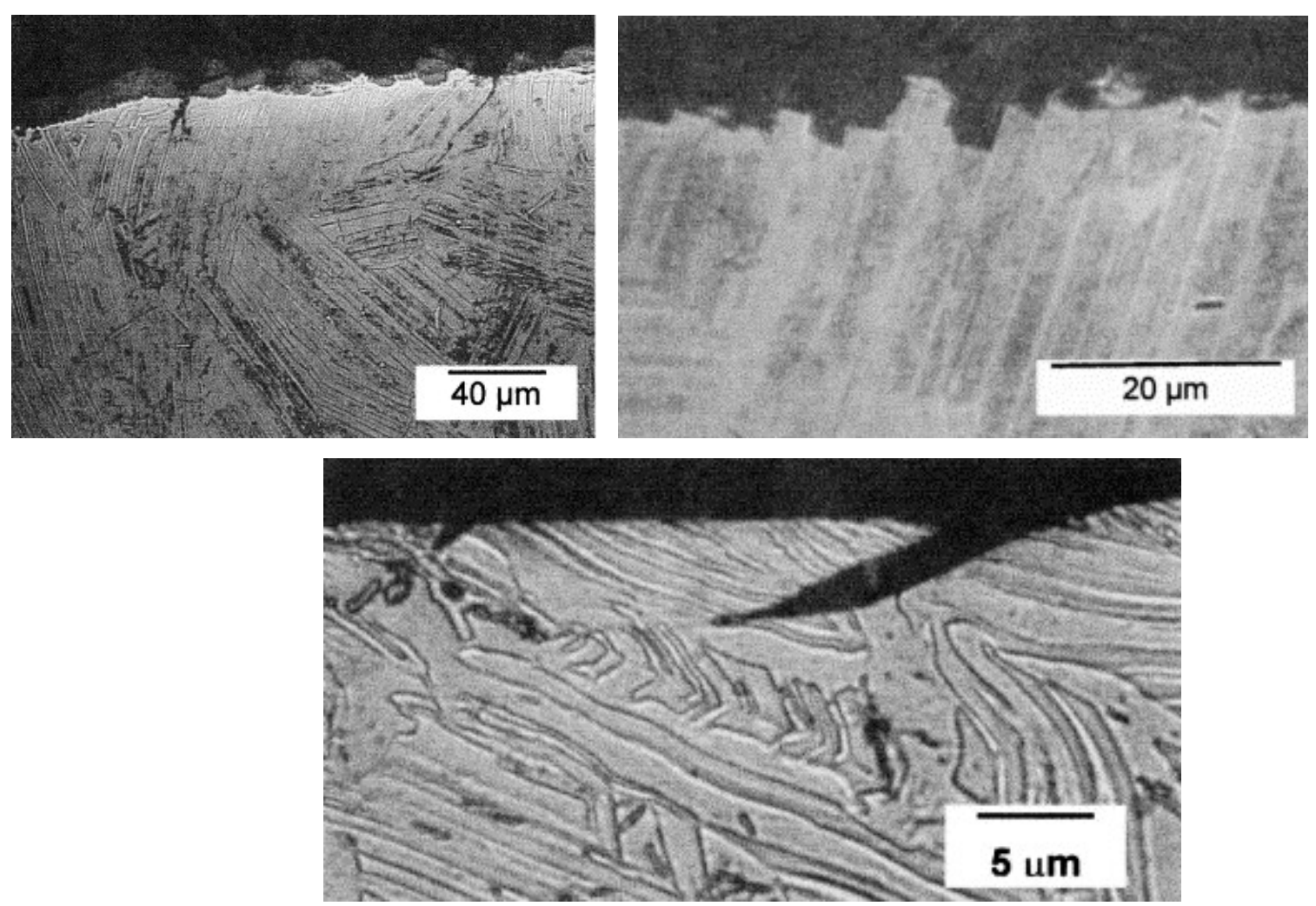

Fig. 7 (a) Crack morphology of EDT specimens; (b) selective etching of the workpiece produced by ECM; (c) crack morphology of turned specimens (Sharman, Aspinwall et al. 2001). 
The fabrication of metallic components using EDM generally creates residual tensile stresses within the surface layers, because it shrinks during cooling while restrained by the adjacent cooler interior material. This effect is exacerbated by the low thermal conductivity of titanium. Tensile residual stresses in Ti-6Al-4V plate machined by micro-EDM can be as high as $350 \mathrm{MPa}$ at depths up to $12 \mu \mathrm{m}$ (Murali and Yeo 2005). In addition, it can be $250 \mathrm{MPa}$ at depths up to approximately $40 \mu \mathrm{m}$ in titanium-alloy bars (Stefanescu, Truman et al. 2006). These levels of measured residual stresses are a significant fraction of the fatigue limit, which directly contribute to reduce the fatigue strength.

It is well-known that surface finish can influence the fatigue life of materials quite strongly. Influential parameters available in wire EDM of Ti-6Al-4V include electrode materials, electrical discharge time and current. These parameters affects the surface roughness and recast-layer thickness, which ultimately contributes to the fatigue performance (Hasçalık and Çaydaş 2007). The average recast-layer thickness could be reduced from nearly 100 to $5 \mu \mathrm{m}$ by reducing both the pulse duration and current with the aid of aluminum wire instead of graphite or copper. The corresponding reduction of surface roughness was from almost 10 to $1 \mu \mathrm{m}$. The surface micro-cracks density could decrease with the increase in pulse current and decrease in pulse duration ( $\mathrm{Yu}$, Xiao et al. 2009). Substantial improvement in the quality of EDM surfaces can be achieved through the use of "minimum damage generator technology” (Aspinwall, Soo et al. 2008) where pulse waveform and frequency varied in addition to electrical current. Average surface roughness below $0.5 \mu \mathrm{m}$ and negligible thickness of recast layer can be achieved with both Inconel 718 and Ti-6Al-4V specimens using this technology (Mower 2014). During high-cycle fatigue of many metals, the majority of cyclic lifetime (up to 90\%) is consumed during the creation of an initial flaw, or sub-critical crack (Newman, Phillips et al. 1992, Nicholas 2006). The presence of micro-cracks in brittle, thermally-processed surface layers - typical of EDM processing - creates ripe for pre-existing flaws to exist (Pramanik, Basak et al. 2015). In such cases, it is expected that the lifetime of parts placed into cyclic stress conditions would be abbreviated, relative to nominally similar components in absence of such defects.

Tensile fatigue strength of specimens turned, ground with "low stress" and mechanically polished, and electro-polished varies by more than an order of magnitude at a given stress level. This suggests that a "short-life" mode of fatigue crack initiation evolves at near-surface alpha grains that are suppressed by polishing process (Golden, John et al. 2010). The table 1 summarises the major studies on the effect of machining on fatigue strength of titanium alloys. 
Table 1 Effect of machining on fatigue strength of titanium alloys

\begin{tabular}{|c|c|c|}
\hline $\begin{array}{l}\text { Reference and } \\
\text { test type }\end{array}$ & Machining process & Conclusion \\
\hline $\begin{array}{l}\text { (Mantle and } \\
\text { Aspinwall 1997) } \\
\text { Rotary bending } \\
\text { fatigue test. }\end{array}$ & $\begin{array}{l}\text { Turned at speed of } 10 \& 25 \mathrm{~m} / \mathrm{min} \text {, } \\
\text { feed of } 0.1 \& 0.05 \mathrm{~mm} / \mathrm{rev} \text { and } \\
\text { depth of cut of } 0.3 \mathrm{~mm} \text { are noted. }\end{array}$ & $\begin{array}{l}\text { The scatter of the results for the turned } \\
\text { specimens is quite high at all stress levels. The } \\
\text { fatigue life of turned specimens diminishes at } \\
\text { higher stresses because of the cracks initiation } \\
\text { at higher stresses. No clear trends of the fatigue } \\
\text { lives of samples are noted. }\end{array}$ \\
\hline $\begin{array}{l}\text { (Bentley, Mantle } \\
\text { et al. 1999) } \\
\text { Four-point bend } \\
\text { (tension-tension) } \\
\text { fatigue test. }\end{array}$ & $\begin{array}{l}\text { Ground specimens were machined } \\
\text { on a surface grinding unit with } \\
\text { conventional SiC abrasive wheels. } \\
\text { Milled specimens were produced } \\
\text { by four-flute, coated, cemented } \\
\text { tungsten carbide ball nose end } \\
\text { tools. }\end{array}$ & $\begin{array}{l}\text { A reduction in fatigue life was noted due to } \\
\text { finish grinding compared to that of rough } \\
\text { grinding and polishing. The fatigue strength } \\
\text { was substantially increased by milling in spite } \\
\text { of surface cracks and deformed lamella. It is } \\
\text { likely that this was due to compressive residual } \\
\text { stresses near the surface and/or deformation of } \\
\text { the lamellae restricting crack growth. }\end{array}$ \\
\hline $\begin{array}{l}\text { (Stráský, Janeček } \\
\text { et al. 2011) } \\
\text { Rotary bending } \\
\text { fatigue test. }\end{array}$ & $\begin{array}{l}\text { EDM with graphite electrodes and } \\
\text { using hydrocarbon oil as dielectric } \\
\text { liquid. High peak current of } 29 \mathrm{~A} \\
\text { was employed. The samples were } \\
\text { electrolytically polished at the } \\
\text { temperature of }-20^{\circ} \mathrm{C} \text { and removed } \\
100 \mu \mathrm{m} \text { from the surfaces after } \\
\text { machining. }\end{array}$ & $\begin{array}{l}\text { Very low fatigue endurance of electro-eroded } \\
\text { (EDM processed) specimens. This was caused } \\
\text { by tensile stresses in near-surface regions, pre- } \\
\text { existing micro-cracks and by high surface } \\
\text { roughness. The fatigue limit is less than } \\
100 \mathrm{MPa} \text { for the samples after EDM while that } \\
\text { of electro-polished specimens produced a } \\
\text { fatigue limit of approximately } 550 \mathrm{MPa} \text {. Both } \\
\text { transcrystalline and atypical faceted fractures } \\
\text { were initiated. }\end{array}$ \\
\hline $\begin{array}{l}\text { (Mower 2014) } \\
\text { Tension-tension } \\
\text { fatigue test where } \\
\text { cyclic loading } \\
\text { used a sinusoidal } \\
\text { waveform at } \\
10 \mathrm{~Hz} \text {. }\end{array}$ & $\begin{array}{l}\text { Specimens produced by EDM were } \\
\text { treated by (i) bead blasting using } 50 \\
\mu \mathrm{m} \text { silica beads from a } 2.4 \mathrm{~mm} \text { in } \\
\text { diameter nozzle at } 400 \mathrm{kPa} \text { in } \\
\text { pressure, (ii) electrochemically } \\
\text { polished using nitric acid based } \\
\text { solution to remove } 20 \mu \mathrm{m} \text { layer } \\
\text { from all surfaces, (iii) } \\
\text { electrochemically polished and } \\
\text { thermal stress-relieved } 594^{\circ} \mathrm{C} \text { for } \\
\text { two hours, and (iv) chemically } \\
\text { milled using a nitric acid based } \\
\text { solution to remove } 10-20 \mu \mathrm{m} \text { from } \\
\text { all surfaces. }\end{array}$ & $\begin{array}{l}\text { EDM process reduces fatigue strength by 15- } \\
30 \% \text { when compared to that machined } \\
\text { conventionally. This strength degradation is } \\
\text { attributed to the presence of stress- } \\
\text { concentrating defects within the EDM recast } \\
\text { layers. Specimens fabricated with the EDM } \\
\text { process were shown to create the roughest } \\
\text { surfaces. Post-processing with either } \\
\text { electrochemical polishing or bead blasting was } \\
\text { demonstrated to alleviate the deleterious effects } \\
\text { of EDM, thereby restoring the intrinsic fatigue } \\
\text { behaviour, as indicated by the crack initiation } \\
\text { at interior locations. }\end{array}$ \\
\hline $\begin{array}{l}\text { (Sharman, } \\
\text { Aspinwall et al. } \\
\text { 2001) } \\
\text { Tension-tension } \\
\text { fatigue test }\end{array}$ & $\begin{array}{l}\text { The turned samples were made } \\
\text { under operating conditions that } \\
\text { cause the minimal surface damage. } \\
\text { The ECM specimens were initially } \\
\text { turned oversize and subsequently } \\
\text { machined to remove } 250 \mu \mathrm{m} \text { from } \\
\text { the test surfaces. Two levels of } \\
\text { EDT operating energy were }\end{array}$ & $\begin{array}{l}\text { The presence of cracks penetrating into the } \\
\text { bulk of fatigue specimens, in combination with } \\
\text { the presence of tensile residual stresses, } \\
\text { resulted in the substantially reduced fatigue life } \\
\text { of the EDT specimens compared to those that } \\
\text { had been turned and ECMed. The lower life of } \\
\text { EDT-H, as compared to EDT-L specimens, } \\
\text { reflects the presence of deeper cracks and }\end{array}$ \\
\hline
\end{tabular}




\begin{tabular}{|l|l|l|}
\hline & $\begin{array}{l}\text { selected, one using high energy } \\
\text { parameters (EDT-H) to provide } \\
\text { specimens with deep cracks and } \\
\text { one using low energy parameters } \\
\text { (EDT-L) to produce shallow } \\
\text { cracks. }\end{array}$ & $\begin{array}{l}\text { higher tensile residual stresses. It is likely that } \\
\text { the higher fatigue life of turned specimens was } \\
\text { due to the highly compressive residual stresses } \\
\text { present in the machined surfaces. }\end{array}$ \\
\hline
\end{tabular}

\section{Stainless steel}

Machining of steels alters the surface layers of workpieces, which produces surfaces that are harder/softer than those of bulk materials (Kahles and Field 1967, Griffiths 1987).

\subsection{Effect of turning}

Thiele and co-workers (Thiele, Melkote et al. 1999) studied the influences of workpiece hardness on residual stresses of hardened AISI 52100 steel surface produced by finish hard turning. For the considered experimental conditions and cutting edge geometry, it was noted that the axial stress component for the workpiece with higher hardness is more compressive. The microstructural analysis reveals that three basic microstructural patterns exist on the workpiece surface such as continuous white, intermittent white and dark layers. These layers are created by heating and successive cooling of machined surfaces during the machining process. The white layers are created by heating the samples above the $\alpha-\gamma$ phase transformation temperature and successive quick cooling during the cutting process. Dark layers are composed of over-tempered martensite with easy etching. Dark layers are typically located beneath continuous white layers and, below and adjacent to intermittent white layers. The interior surfaces of the workpieces are tempered martensite. Surface residual stresses in the axial and hoop directions are associated with individual microstructural patterns. Specifically, compressive residual stresses in the hoop and axial directions are evident when the workpiece surfaces contain continuous white layers (Abrāo and Aspinwall 1996). The main cause of compressive residual stress formation in samples exhibiting continuous white layers to contribute volume expansion is phase transformation. During machining, the tempered martensite in the workpiece surface transforms to austenite. Rapid cooling causes the generation of untempered martensite, which attempts to inflate. The interior workpiece material places the surface layers in compression residual stresses. Samples that show dark layers on the workpiece surfaces normally correlate with tensile residual stresses in the hoop and axial directions. By considering the thermal expansion and subsequent cooling of the workpiece surfaces, constrained by the workpiece interior, the correlation between formation of dark layers and tensile residual stress could be explained. Thermal gradient produced by the cutting process causes the 
surface layers to expand more than inner layers, eventually leading to plastic deformation. Upon cooling, the surface layers attempt to shrink to a length smaller than the interior layers, and are placed in residual tension to maintain equilibrium. Finally, surface layers consisting of intermittent white layers may undergo tensile or compressive stresses depending on the amount of existing white layers. Large amounts of intermittent white layers correlate with compressive residual stress in the hoop and axial directions or vice versa (Thiele, Melkote et al. 1999).

Javidi and co-worker (Javidi, Rieger et al. 2008) investigated the correlation between turning parameters, surface integrity and fatigue properties of $0.34 \%$ carbon steel type $34 \mathrm{CrNiMo}_{6}$ (quenched and tempered). A larger feed gives quicker machining but a higher surface roughness. The larger nose radius generates lower surface roughness but an extremely long nose radius may induce vibration affinities, unacceptable chip breaking and higher tool wear owing to inadequate cutting edge engagement. An increase of the nose radius of the insert reduces the compressive residual stresses. Higher compressive residual stress induces longer fatigue life and the influence of residual stresses on fatigue behaviour outperforms that of surface roughness (Sasahara, Obikawa et al. 2004, Javidi, Rieger et al. 2008). Fig. 8 shows the influence of nose radius on S-N curve for 34CrNiMo6 steel. It clearly indicates that the fatigue strength of the components produced by turning increases with the decrease in nose radius. 


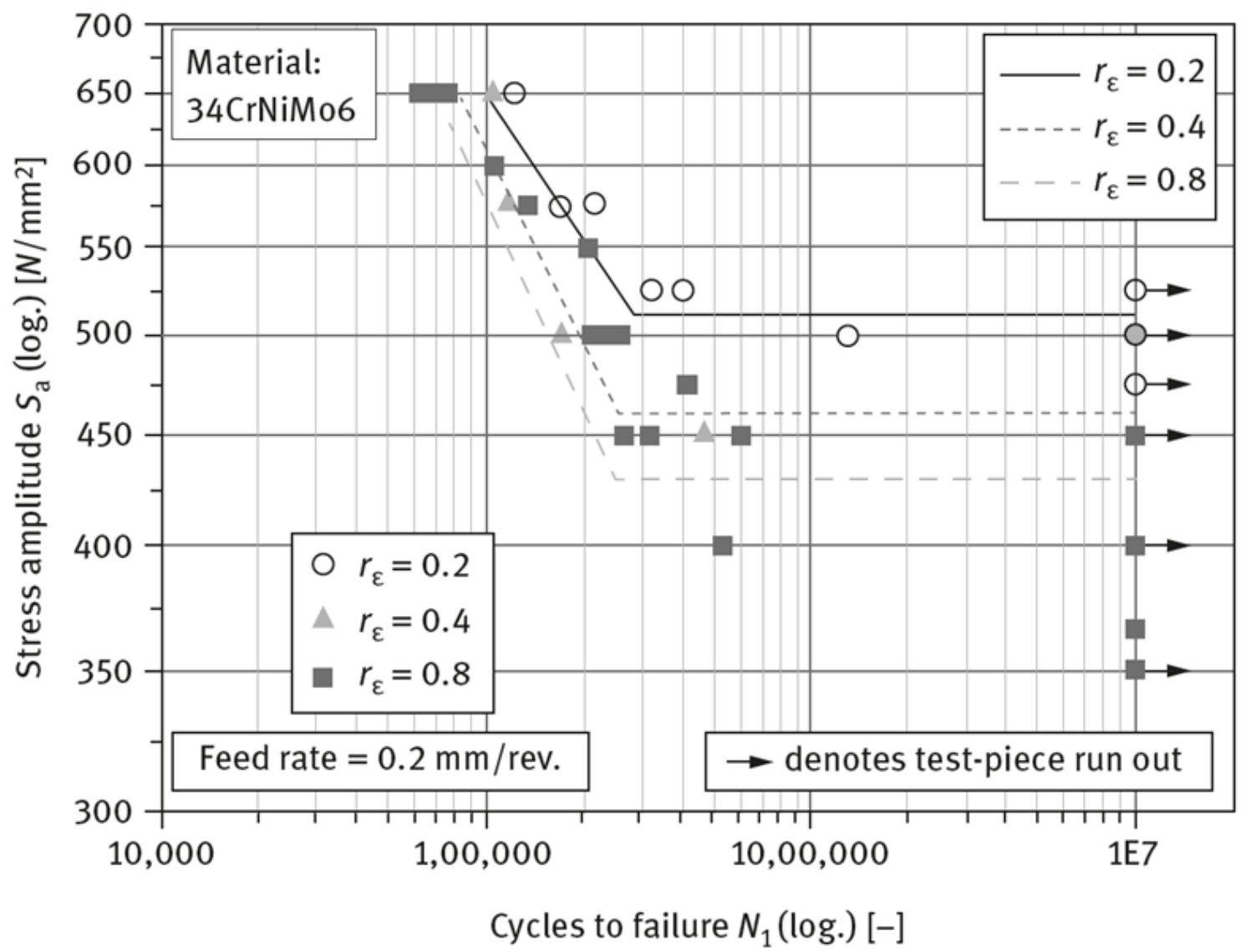

Fig. 8 S-N curves of samples turned with inserts of different nose radius (Javidi, Rieger et al. 2008)

Lower feed causes the surface residual stress to swing towards the compression, which influences the fatigue behaviour significantly. The trend towards higher tensile stresses due to the increase of temperature during machining at the higher feed (Outeiro, Dias et al. 2004). The compressive residual stresses that are ahead of the crack tip are detrimental to the propagation of cracks. A crack that starts beneath the machined surfaces might propagate until a compressive stress region where the crack will be retarded till the relaxation of stresses. The higher feed generates tensile residual stress zone, and therefore the crack propagates until rupture. If the probability to start cracks from the surface increases, the crack initiation will be first in samples produced by small feed, which then propagates till the compressive stress zone. The samples with higher compressive residual stresses on the surfaces require a longer time to start and spread a crack from the surfaces (Schwach and Guo 2006). The cracks up to $5 \mu \mathrm{m}$ deep in the surfaces produced by turning can be compensated for by compressive residual stresses, which further decreases the applied tensile stress. In a similar manner, turning becomes more favourable than grinding with respect to the fatigue behaviour of hardened bearing steel (Abrāo and Aspinwall 1996). High speed milling with the proper machining conditions might increase fatigue strength (Bentley, Mantle et al. 1999). The process causes higher plastic deformation/strain hardening 
and lower temperatures, which generates compressive residual stresses at/adjacent to the machined surfaces (Novovic, Dewes et al. 2004).

The effect of the cutting edge geometry of turning tools on the fatigue life was investigated by Sasahara (Sasahara 2005). The residual stresses in the hoop direction in the surface machined by chamfered cutting edge were more compressive than those of the machined surfaces produced by sharp cutting edges. However, the variation of hoop residual stresses is minor between surfaces machined by the chamfered and sharp edge tools. The smaller corner radius of chamfered tools increases the hardness of machined surfaces, which indicates that the plastic deformation of the machined surfaces increases with decreasing the corner radius. This is another reason of the wide variation for the fatigue life of the specimens with identical surface roughness. Effects of hardness and axial residual stresses on fatigue life at different edge preparation and cutting conditions are given in Fig. 9. The fatigue life nearby point A is short where the tensile residual stresses and lower surface hardness are noted. Conversely, the fatigue life nearby point $B$ is longer where the axial residual stress is close to neutral and the hardness is more than $290 \mathrm{HV}$. Higher compressive residual stresses and hardness that are identical to those of point $A$ are noted around the point $C$ where fatigue life is higher than that around point $A$. Therefore, high compressive residual stresses and high surface hardness are necessary for longer fatigue life, as shown in the region D in Fig. 9 (Sasahara 2005).

All normal residual stress components in the finish hard turned through-hardened AISI 52100 steel becomes more compressive with rise of cutting edge hone at a constant feed rate. The stresses in the radial direction are generally smaller than the other stress components (Thiele, Melkote et al. 1999). The principal stresses produced by each edge preparation are somewhat different, despite the similarities in the normal stress components (Thiele, Melkote et al. 1999). The fatigue life increases with the increase of surface hardness due to the increase of the yield strengths of surface layers by the work hardening. The work hardening and the residual stress depend on each other through the machining processes. The distribution profiles of residual stresses and hardness also influence the fatigue life. The residual stresses and the surface hardness can be regulated through the proper selection of feed rate, corner radius and cutting edge radius during a machining process. The residual stress becomes nearly zero and the surface hardness hardly changes when the corner radius of cutting tool is small. Machining by cutting tools with a smaller corner radius at the low feed rate increases the fatigue life of the machined components. Therefore, the correlation between residual stresses and the surface hardness might be evaluated to identify optimum machining parameters (Sasahara, Obikawa et al. 2004, Sasahara 2005). 
The increase of cutting edge radius reduces the real rake angle on the way to the negative values (Sasahara, Obikawa et al. 2004). Hence, the influence of larger edge radius is comparable to a negative rake angle (i.e., inducing compressive residual stresses underneath the machined surfaces). Abhang et al. (Abhang 2010) argued that the contact area for heat dissipation increases as the radius of tool nose increases, which generates lower tensile residual stresses on the machined surfaces as the local temperature along the cutting edge decreases. However, with the increase in contact area, the friction between tool and workpiece is enhanced as well, which increases the heat generation owing to the friction and contributes to higher tensile residual stresses. Simultaneously, lower tool/part pressure per area decreases plastic deformation as the contact area increases. Hence, the increase of tool nose radius infers increased temperatures due to the friction and lower plastic deformation, thus resulting in more tensile surface residual stresses (Sasahara, Obikawa et al. 2004).

Garcia et al., (García Navas, Gonzalo et al. 2012) concluded that the higher cutting speed tends to induce tensile residual stresses, but the tendency is not certain as to the peak width for AISI 4340 steel. Increased cutting speed enhances the local temperature close to the cutting edge, which promotes tensile residual stresses (thermal stresses) on the machined surfaces. If the generated temperature is higher at the surfaces and the depth of heat infiltration is lower, the martensite transformation in quenching is likely to occur, which facilitates the generation of the compressive residual stresses.

Rech et al. (Rech and Moisan 2003) and M'Saoubi et al. (M’Saoubi, Outeiro et al. 1999) used coated tools with stable cutting parameters (i.e., reduced cutting forces and better chip formation), which generated less tensile residual stresses because of better tribological behaviour (i.e. lower friction and lower heat generation during machining). However, the coating of inferior thermal conductivity hinders the machining heat from degrading the cutting tool and extends the tool life, but tends to transmit higher amounts of heat to the workpieces. This heating of the workpieces could be accounted for tensile residual stresses when using coated tools (García Navas, Gonzalo et al. 2012). 


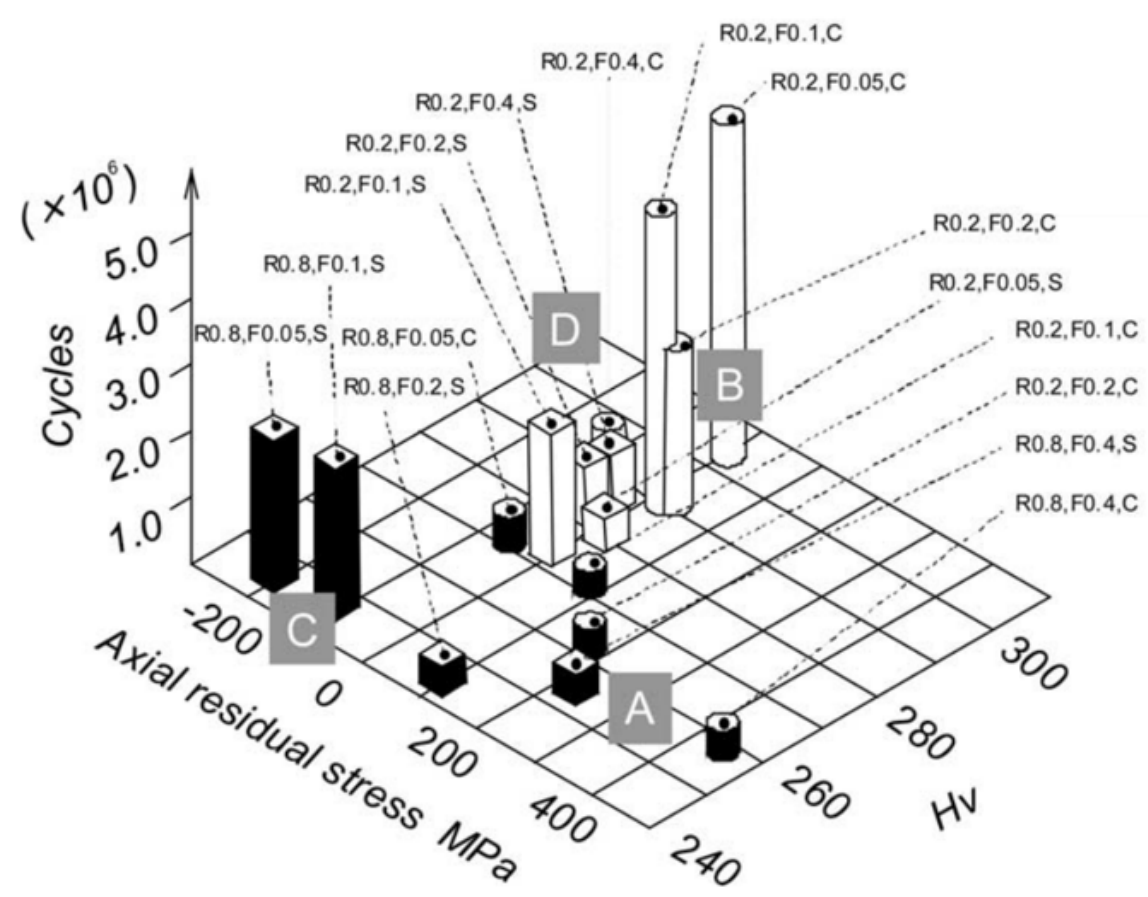

Fig. 9 Effect of axial residual stresses and hardness on fatigue life at different edge preparation and cutting conditions (where $R$ and $F$ represent the roughness and the feed rate, respectively. $\mathrm{S}$ indicates sharp edges and C means chamfered edges) (Sasahara 2005).

Tool wear is unavoidable during machining processes, which makes cutting tools blunt. Thus the wear of the tool increases the heat generation and thus the increase of residual stresses. Dry machining increases the heat generation in the contact areas (Fetullazade, Akyildiz et al. 2010). Measured residual stresses on the surfaces dry machined with worn tools may exceed the yield strength of SAE 4340 steel. This is due to sever plastic deformation and very high strain hardening of the machined surfaces. In the same fashion, heating from the friction might change the phase and generate residual stresses. Hardening of machined surface layers is influenced by elastic and plastic behaviour of materials, thermal expansion coefficient and similar physical properties (Fetullazade, Akyildiz et al. 2010). The machining conditions influence the endurance limits of the threaded SAE 4340 steel over a wide range. The most noteworthy thread machining factor to influence the fatigue behaviour is tool wear, which is followed by the machining speed. However, the radial feed and thread cutting method are less influential. Residual stresses and strain hardening both need to be considered for the design purposes that depend on the material and machining parameters (Fetullazade, Akyildiz et al. 2010).

The residual stresses on the machined surfaces rest on the materials being machined and on the cutting conditions (Field 1971). Akyildiz and co-workers (Akyildiz and Livatyali 2010) demonstrated that the machining conditions such as cutting speed, feed rate, and tool nose radius had great effect on the fatigue behaviour and surface quality of machined components (Arola and Williams 2002, Dahlman, 
Gunnberg et al. 2004). A complete knowledge on the influence of surface topography on the fatigue behaviour can only be obtained by investigating residual stress-free specimens and specimens where no phase change occurred. Unluckily, stress relieving treatments after machining processes alters the metallurgical state on the machined surface. Taylor and Clancy (Taylor and Clancy 1991) studied the fatigue behaviour of stress free En19 steel (equivalent to AISI 4140) and found that comparatively low surface roughness ( $R a 0.5-1.4 \mu \mathrm{m}, R t 7-14 \mu \mathrm{m})$ generated by modest grinding decreases the fatigue life compare to that of polished specimens where the surface roughness ( $R a 0.1-0.3 \mu \mathrm{m}, R t 3-5 \mu \mathrm{m})$ is further low. The surfaces produced by grinding show higher fatigue strength than that of milled surfaces with identical surface finish $(R a, R t)$. This resulted from the rounded feed marks generated by milling, which initiated premature cracks in the normal direction to the axis of samples. It was suggested that the roughness parameters such as $R t$ and $R z$, are more suitable indicators of fatigue behaviour than $R a$ as they revealed the 'worst' flaws existing on the machined surfaces.

\subsection{Effect of grinding}

The fatigue strengths from tension-tension tests of through-hardened AISI 52100 steel (60-62 HRC) machined by different processes are given in Fig. 10 (Smith, Melkote et al. 2007) with with various surfaces of specimens clearly shown. Those are: (a) hard turned surfaces with continuous white layers (HTWL), (b) hard turned surfaces with no white layers (HTnoWL), (c) ground surfaces (G), (d) hard turned surfaces (uninterrupted white layer) with super finish (HTSF), and (e) ground surfaces with super finish (GSF). The hard turned specimens showed better performance in all cases when compared with ground counterparts. The average fatigue life of HTWL specimens is 56,867 cycles as opposed to 27,360 cycles for the $G$ specimens based on a traditional assessment. In reality, the poorest HTWL specimens have a fatigue life of 16,106 cycles, which go beyond the average life of $G$ specimens when the outlier is removed. The average value for the HTnoWL surfaces is similar to that of ground specimens (24,657 versus 27,360 cycles) even in the absence of white layer. In the same manner, the average fatigue life of the HTSF specimens (323,897 cycles) appears to be far higher than that of GSF counterparts $(19,427)$. The discrepancy in the fatigue behaviour is higher and such distribution is characteristic of high cycle fatigue testing. The harsh manufacturing parameters and discrepancy in tooling are two additional sources of this variation (Smith, Melkote et al. 2007). 


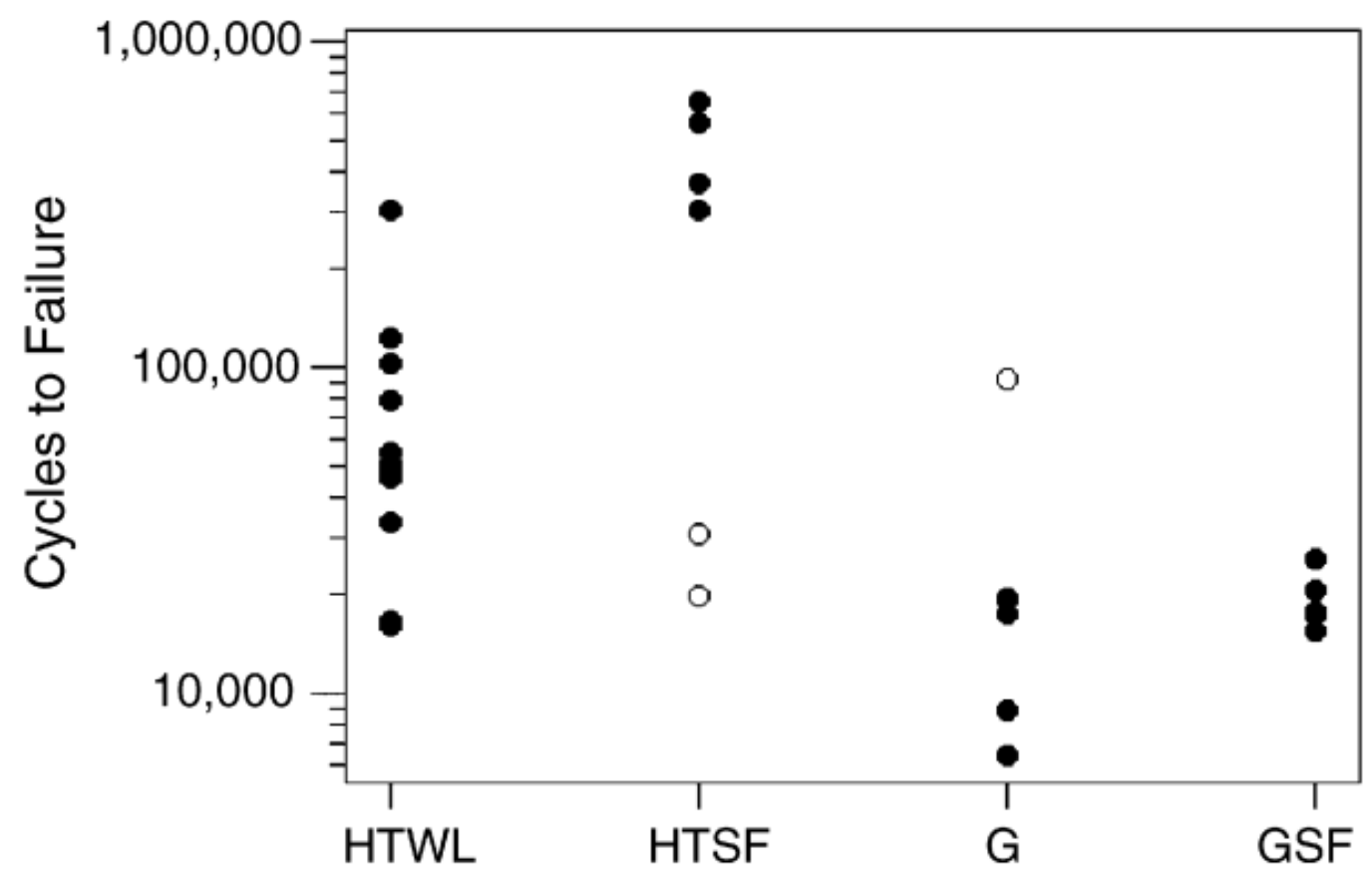

Fig. 10. Axial high cycle fatigue life results (Smith, Melkote et al. 2007)

It is well accepted that the increase of compressive residual stresses substantially increases the fatigue life with such a relation that does not exist between surface finish and fatigue life. This indicates that the most significant dissimilarity between the surface integrity of specimens is the dissimilarity in the residual stress profiles. In the absence of obvious surface defects, the fatigue performance of the specimens is ascribed to residual stress profiles, in which the fatigue life rises with the increase in compressive residual stress. This tendency is expected between the HTnoWL and G specimens along with the HTSF and GSF counterparts. Nevertheless, the fatigue behaviour of HTWL specimens indicates that the existence of white layers does not change this tendency. This shows that the influence of the hard turning method on the fatigue behaviour of specimens is determined mainly by the subsequent profiles of residual stresses. (Smith, Melkote et al. 2007). Fig. 11 plots the effect of the surface residual stresses in the axial direction on the average fatigue life. The figure demonstrates that the fatigue life of machined specimens is approximately linearly proportional to the compressive residual stresses of machined surfaces. 


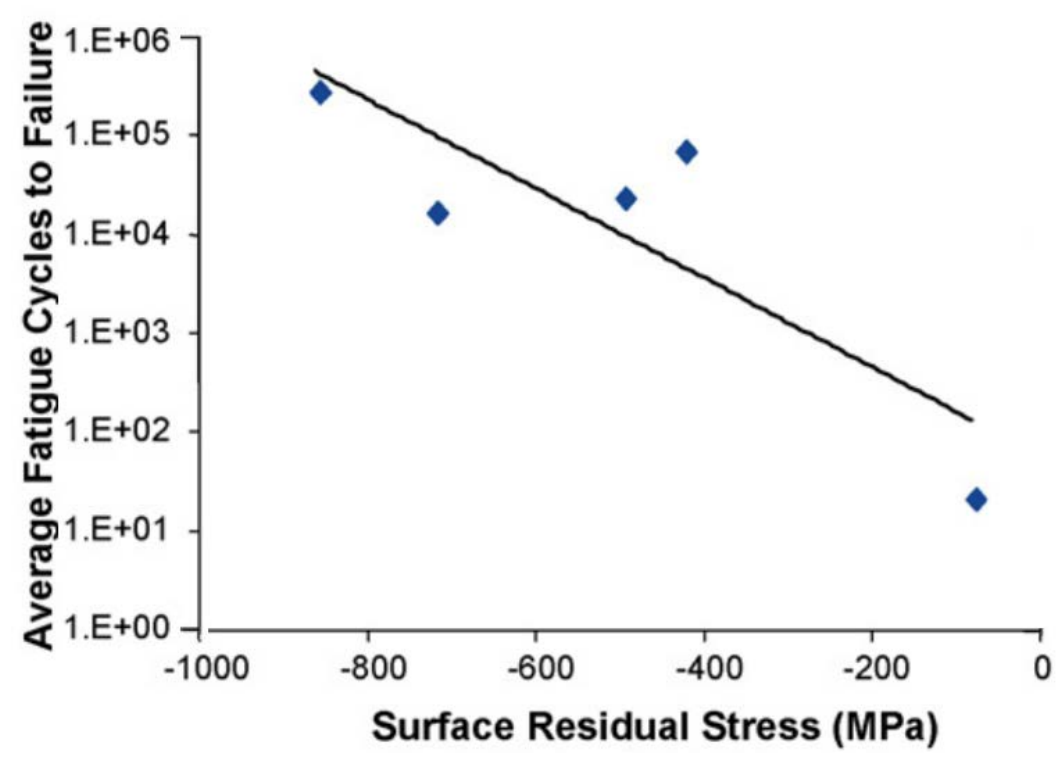

Fig. 11 Fatigue life vs. surface residual stress in the axial direction (Smith, Melkote et al. 2007)

Rolling contact fatigue tests were performed to study the consequence of precision hard turning and grinding on the fatigue life by Matsumoto and co-worker (Matsumoto, Hashimoto et al. 1999). The change of the surface microstructures after grinding along with hard turning during the process of making bearings with optimum conditions was not manifested. The most important dissimilarity between ground bearings and hard turned bearings after super finishing was the residual stress profile and depth of compressive residual stresses. Fig.12 compares the residual stress profile in the ground and then super finished surfaces to that in the hard turned and super finished surfaces. After grinding and super finishing, higher compressive residual stress is induced near the surfaces, which is yet reduced sharply as the distance increases along the depth from the machined surfaces. In contrast, the residual stresses extend to higher depth from the machined surfaces after hard turning and super finishing. Matsumoto and co-worker (Matsumoto, Hashimoto et al. 1999) reported significant local plastic deformation around micro-cracks during fatigue tests. A clear relation between the depths at which butterflies ${ }^{1}$ were noted and the fatigue life was distinguished, namely the deeper the butterflies, the longer the fatigue life. Therefore, deeper compressive residual stress generated by hard turning is advantageous (Matsumoto, Hashimoto et al. 1999).

${ }^{1}$ This region has the appearance of butterfly wings when viewed in cross sections 


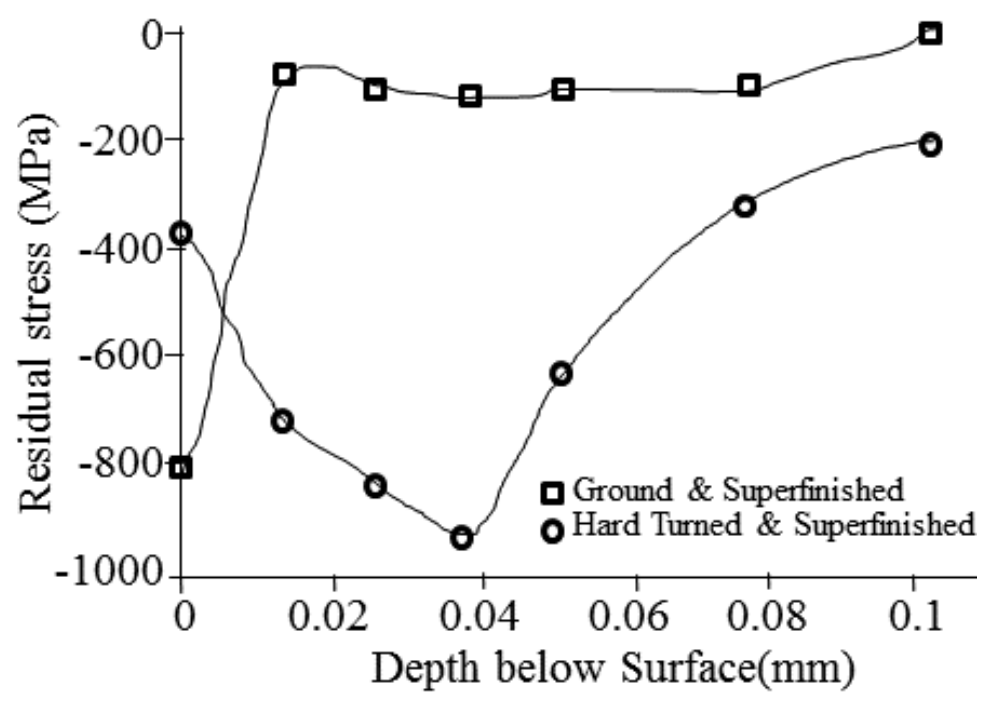

Fig. 12 Residual stresses along the depth of machined surfaces for different machining processes

(Matsumoto, Hashimoto et al. 1999).

The basic dissimilarities in the integrity of hard turned and ground surfaces and the successive influence on rolling contact fatigue behaviour were studied by Hashimoto et al. (Hashimoto, Guo et al. 2006). It was reported that the turning process with the smaller depth of cut and feed rate produces better $(\approx$ $30 \%$ ) surface roughness when compared to that of ground surface. Turned and ground surfaces are not thermally damaged, while grinding temperature has a much deeper excursion on the subsurfaces. It is evidently shown that the subsurfaces have two different zones categorised by a strain hardened zone in near surfaces and a thermally affected zone in the subsurfaces (not softened enough as compared to bulk hardness). White layers do not belong to the strain hardened zone. It is not darker than the bulk material and the thermally affected zone encountered in hard turning as shown in Fig. 13. The dissimilarity of the two zones is just ascribed to their different resistance to etching due to the variation in grain deformation and size (Hashimoto, Guo et al. 2006).
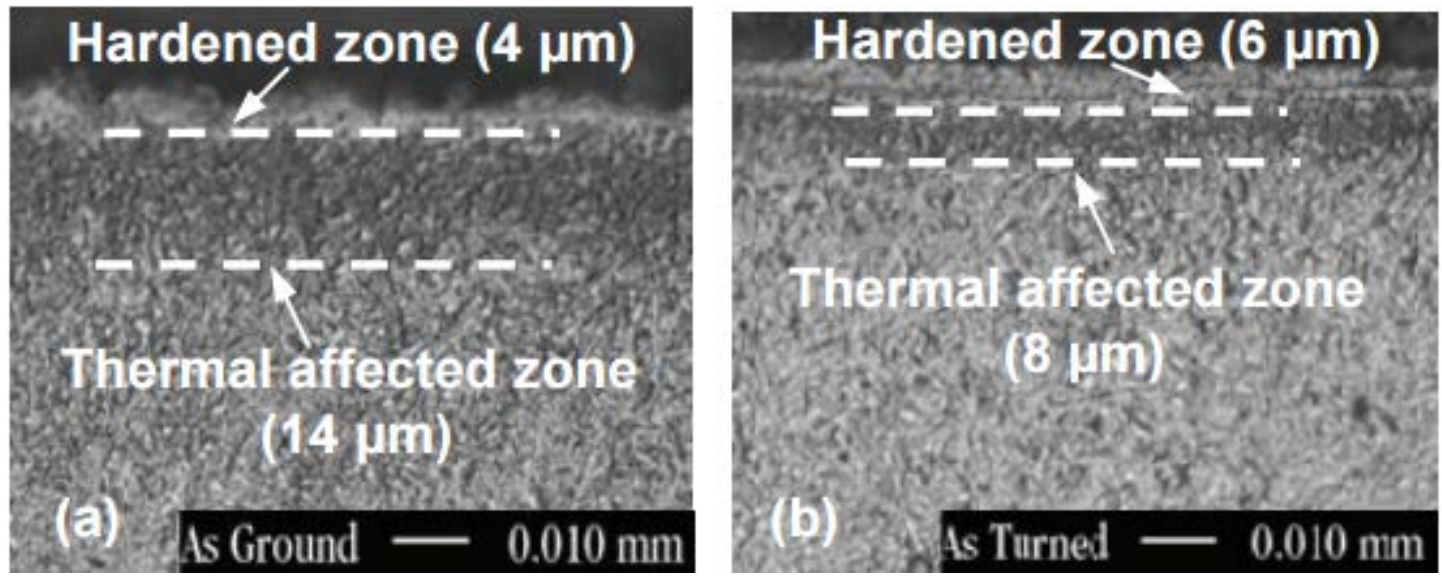

Fig. 13. Hard turned and ground surfaces (Hashimoto, Guo et al. 2006) 
The variation of hardness at different depth may be influenced by different interactions between material phases and indenters. The fundamental mechanism for the harder ground surfaces/subsurfaces is most likely due to the size effect induced by the very high strain gradient during the grinding process. The lower down feed in grinding incurs very high strain gradient on near surfaces, though comparatively high depth of cut in turning may significantly decrease the size effect. The super finished turned surfaces may have 100\% more fatigue life than those of ground specimens with similar surface roughness. The facts that contribute to the inconsistency in fatigue behaviour are the distinct surface structures and properties generated in the processes (Hashimoto, Guo et al. 2006). According to the results of different studies, it could be concluded that the main dissimilarity between hard turning and grinding is that hard turning may induce deeper "surface" compressive residual stresses despite the provision of similar or better surface finish, form and accuracy. Thus, the dissimilar features of residual stresses induced by hard turning and grinding influence the fatigue behaviour of machined components in rolling contact (Guo and Yen 2004).

\subsection{Effect of milling}

The effect of grinding and fly cutting (single point milling) methods on the fatigue behaviour of hardened AISI 4340 steel and their relation to surface integrity is studied by Matsumoto and co-workers (Matsumoto, Magda et al. 1991, Matsumoto, Hashimoto et al. 1999). It was noted that the residual stresses produced by the milling process are mostly compressive. The compressive stresses are well known to improve fatigue strength in some cases. Three residual stress distributions on the machined surfaces measured parallel to the machining direction are shown in Fig. 14. The specimens were produced by grinding in the direction of the length of the specimen, fly cutting with feeding in the direction perpendicular to the length of the specimen, and fly cutting with feeding in the direction of the length of the specimen. All specimens carried compressive residual stresses except the top layer of machined surfaces milled perpendicular to length. The residual stress distribution produced by grinding had a high peak compressive residual stress on the machined surfaces. The stress on ground surfaces was shallow with a very steep gradient, while as for the others it reached much deeper. It appears that the residual stresses produced by grinding lie in a very shallow depth, and it might not have a noticeable influence on the fatigue limit. Conversely, the higher and deeper compressive residual stresses on the fly cut surfaces increased the fatigue limit in this investigation. It should also be noted that the residual stresses in the deeper layers becomes a more important factor, when the nucleation of a crack starts from inclusions in the subsurfaces. The investigation on the cross sectional structures of three machined surfaces indicates that there is no distinct structural change on the machined surfaces. The measured 
roughness of the ground surfaces had the largest maximum height $R_{\max }$ and the lowest endurance limit of fatigue (Matsumoto, Magda et al. 1991).

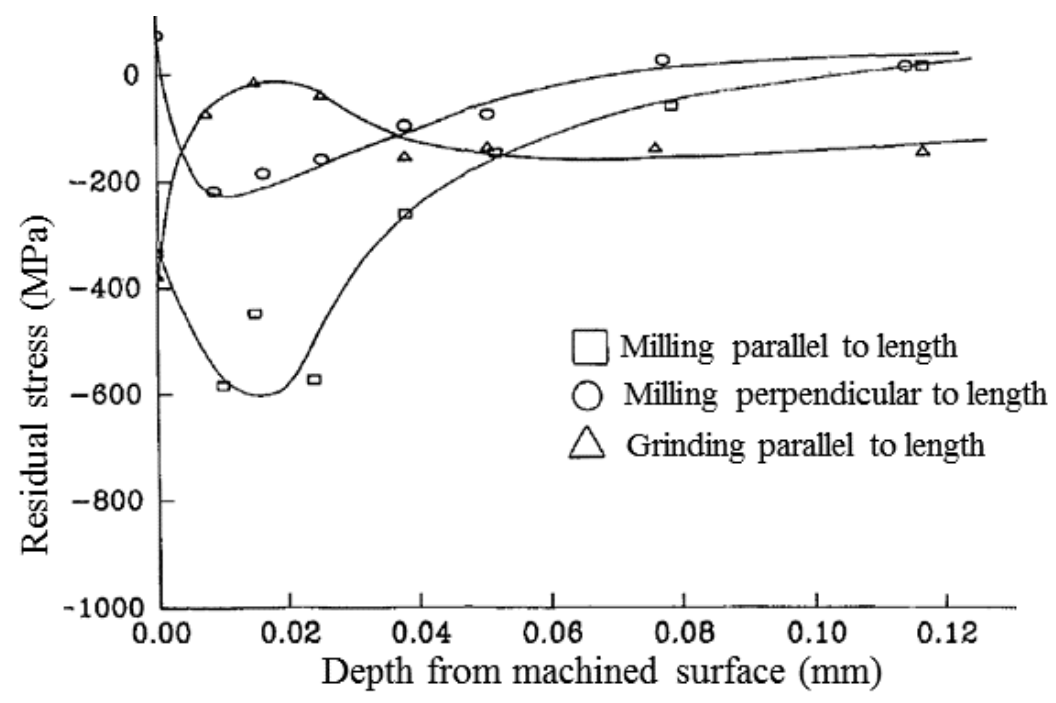

Fig. 14 Residual stresses measured in the direction of machining process (Matsumoto, Magda et al. 1991).

There are three sources that are responsible for creating residual stresses on the machined surfaces. These are a martensitic phase transformation in the near surface structures, yielding surface or near surface elements due to thermal stresses caused by machining heat, and uneven plastic deformation of surface or subsurface elements. Under usual situations, when there is no excessive tool wear or abusive machining practice, very little martensitic formation is observed in the machined surface layer of hardened steel (Matsumoto, Barash et al. 1986).The existence of untempered martensite on the subsurfaces produces a compressive residual stress due to its larger volume. On the other hand, if the temperature rise in that the machining process does not reach the $\alpha-\gamma$ transformation temperature, further tempering can take place. If the further tempering takes place, more martensite is transformed into ferrite and cementite, thus volume reduction near the surfaces takes place. The result is a tensile residual stress on the surfaces. The surface residual stresses on all machined surfaces are also compressive and if there is any tempering, its influence on the residual stresses could be minor.

\subsection{Effect of non-conventional machining}

Electro-discharge machining (EDM) is a high energy density non-contact method (Pramanik 2016), in which layered structures on the machined surfaces are generated due to melting and quick solidification of materials. The EDM of tool steels (Ghanem, Sidhom et al. 2002) creates three noticeable layers, such 
as (a) a "white layer" near the surface, with a dendritic structure resulting from the re-solidification of metal melted during the EDM, (b) a quenched layer with a martensitic structure just beneath the white layer, and (c) a transition zone between the quenched layer and the base material. The EDM specimens demonstrate a higher surface hardening compared to conventionally machined (milled) specimens because of the near-surface phase changes and increased amounts of carbon. Under this circumstance, tensile stress is produced adjacent to the surfaces. A network of micro-cracks is also observed on the surfaces. This scatter of cracks changes significantly of any kind of applied stresses. The cracks initiate and propagate freely to and form an uninterrupted network, which leads to untimely failure of the specimens manufactured by the EDM as compared to specimens manufactured by milling to generate better surface integrity and finish.

The metallurgical alterations of machined surfaces in EDM the near-surface layers occurs due to the sparks that extremely heats locally (up to $10000^{\circ} \mathrm{C}$ ) in a very short time (6 $\left.\mu \mathrm{s}\right)$, and the successive cooling by the dielectric fluid and transfer of heat into the bulk material (Pramanik and Littlefair 2015). The thermal flux evaporates and melts the samples in order to generate craters of different sizes and shapes on the surfaces. Thus an irregular surface profile is generated from this process. The heating effect changes the machined surfaces, and the melted material goes through a "quenched" then to a "tempered" and, to the unaffected bulk material. The changes on the machined surfaces are influenced by thermal behaviour of machined materials and its capacity to harden (Ghanem, Braham et al. 2003). The changes in hardness occur because of chemical and thermal effects (Mamalis 1987) including the increase in carbon content and martensitic formation in the quenched layer. The disintegration of the dielectric causes diffusion of carbon results. The strains caused by the thermal effects and phase transformation after the EDM induce tensile residual stresses on the machined surface. These stresses are partially relaxed at the surfaces because of the cracks produced from the EDM. The diffusion of hydrogen into the machined surfaces after the disintegration of the dielectric fluid causes near-surface embrittlement. Generally the cracks and tensile residual stress distribution on the machined surfaces undermine fatigue behaviour of specimens produced by the EDM. Samples produced by the EDM and milling have similar fatigue properties because of the reduction of residual stresses from substantial cycling strain hardening in low cycle fatigue tests. The spread of fatigue cracks in bulk materials is a key factor to regulate the fatigue behaviour of specimens produced by the EDM and milling in that the hardening embrittlement of changed layers from both methods are nearly undistinguishable. The residual stresses on the machined surfaces have greater influence on the high cycle fatigue properties (Bouzid Saï, Ben Salah et al. 2001), in which 35\% reduction of endurance limit (at $10^{6}$ cycles) was 
shown for specimens by the EDM treatment rather than milling treatment (Ghanem, Sidhom et al. 2002).

Fig. 15 depicts the S-N curves from the axial fatigue tests on AISI 301 membranes produced from diverse manufacturing methods. The results are significantly scattered despite clear common trends. The membranes produced by stamping have a considerably better fatigue life than those produced from laser-cut and abrasive water-jet cut. The top stress to failure of stamped membranes is $15 \%$ higher than that of other processes for 1 million cycles fatigue life. The influence of stress concentration is predominantly significant at the low cycle fatigue behaviour (i.e. where the stress is high). This is evident from the lower fatigue life of laser-cut specimens, as demonstrated in Fig. 22(a), in which each fatigue crack started at a single initiation location on the hole surfaces. Nonetheless, the high cycle fatigue properties of the membranes produced by LBM and AWJ are almost similar. Though the samples produced by AWJ and $\mathrm{LBM}\left(0^{\circ}\right)$ show identical fatigue behaviour, the fatigue life of specimens from $\operatorname{LBM}\left(90^{\circ}\right)$ doubles that of samples produced by $\operatorname{LBM}\left(0^{\circ}\right)$ at identical stresses. Fig. 11 (b) demonstrates the fatigue behaviour of stamped, EDM and EDM-shot peened membranes. The stress for failure for 5 million cycles and low cycle behaviour are almost identical for stamped and EDM-shot peened membranes. The membranes produced from the EDM have 20\% lower fatigue strength at 5 million cycles than that of stamped membranes. Similarly, stamped membranes demonstrate higher fatigue strength that that of EDM at the low cycle (Fordham, Pilkington et al. 1997).
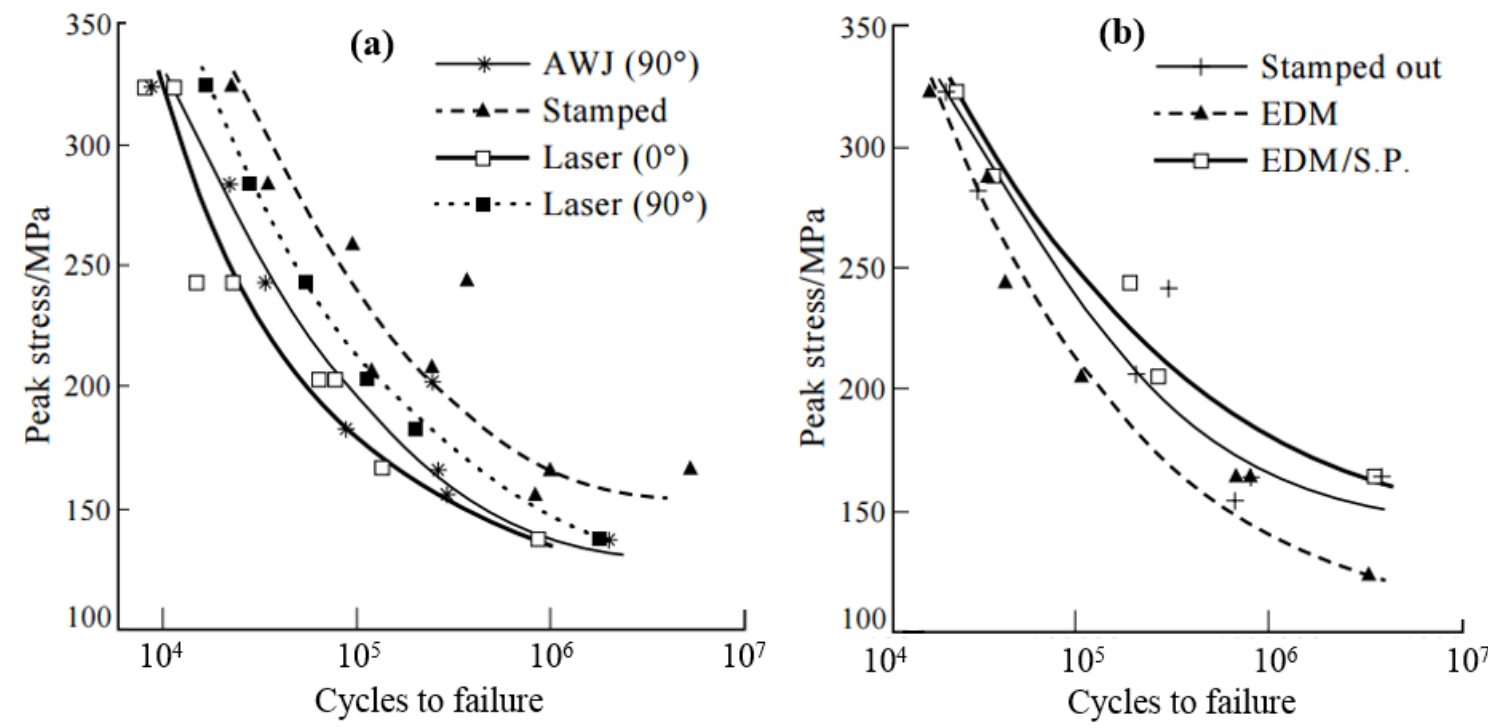

Fig. 15. S-N curves for AISI 301: (a) stamped, LBM and AWJM membranes and (b) stamped, EDM and EDM-SP membranes (Fordham, Pilkington et al. 1997). 
It is proposed that micro-cracks on the machined surfaces with higher surface finish (e.g., polished surfaces), start from slip bands or at grain boundaries (Suhr 1988, Suresh 1998, Dieter 2015). Nevertheless, micro-notches were generated through machining processes (e.g. grinding, turning and milling), concentrated stresses and localised plastic strain with the application of stresses. This happens in a discrete grain as a slip band that outlines the route of shear cracks (Suhr 1988, Novovic, Dewes et al. 2004). Siebel and Gaier (Siebel 1957) has found that the highest depth (Rt) of surface profile generated from machining processes is the most important roughness factor to influence the fatigue behaviour of machined components. The decrease of fatigue endurance limit is proportional to $\log \left(R_{t}\right)$ when the maximum depth of the surface profile is bigger than a certain critical groove depth. The critical groove depth are 1-2 $\mu \mathrm{m}$ for tempered and 4-6 $\mu \mathrm{m}$ for annealed steels, as demonstrated in Fig. 16. It is possible to eliminate the effect of surface finish on fatigue behaviour of machined components by inducing compressive residual stresses on the surface through post-machining mechanical treatment (Novovic, Dewes et al. 2004). The table 2 summarises the major studies on the effect of machining on fatigue strength of stainless steel.
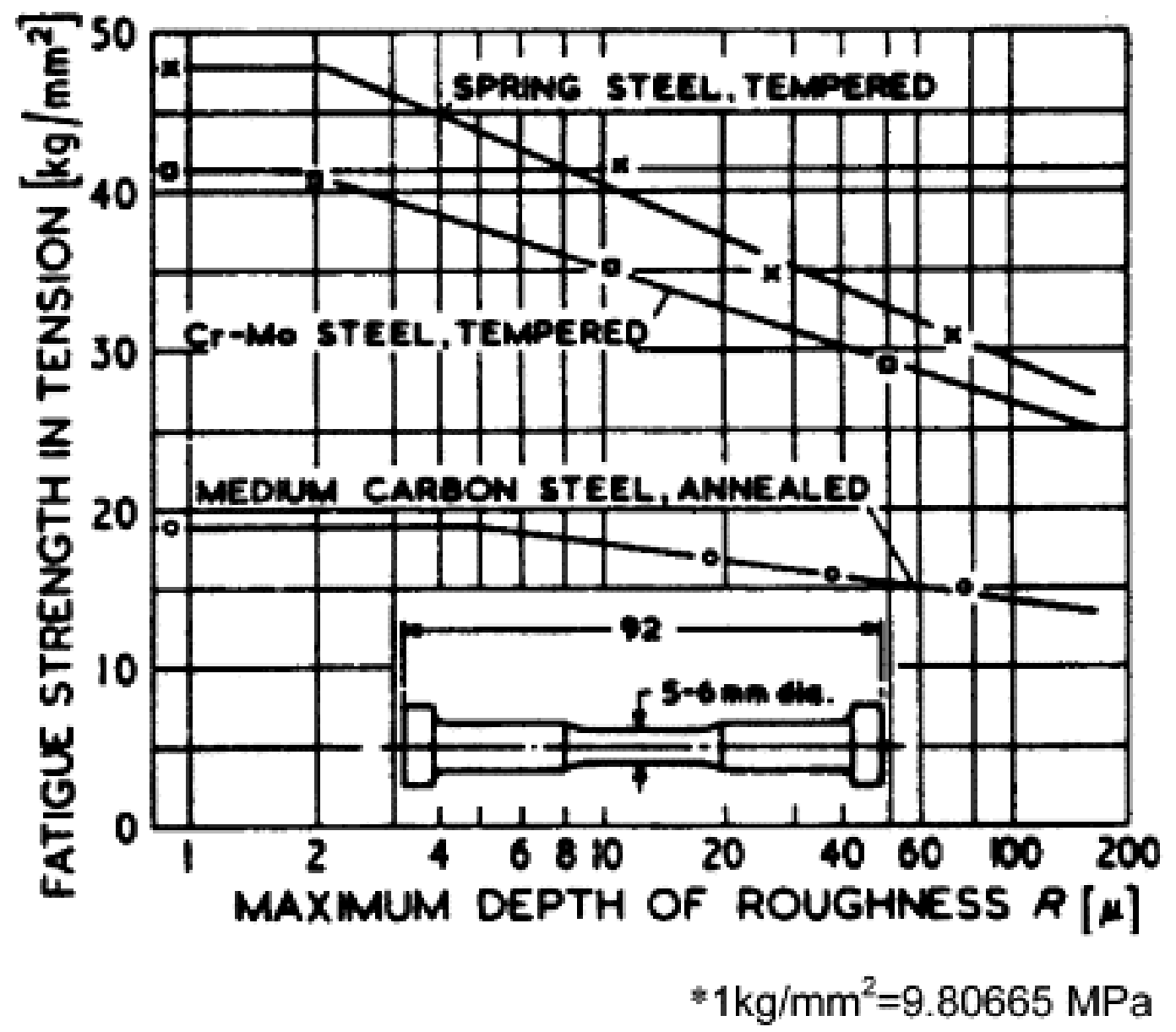

Fig. 16. Effect of maximum depth of surface profile on the fatigue strength of various steels in repeated tension (Siebel 1957). 
Table 2 Effect of machining on fatigue strength of stainless steel

\begin{tabular}{|c|c|c|}
\hline $\begin{array}{l}\text { Reference and } \\
\text { test type }\end{array}$ & Machining process & Conclusion \\
\hline $\begin{array}{l}\text { (Javidi, Rieger et } \\
\text { al. 2008) } \\
\text { Rotating bending } \\
\text { fatigue tests at } \\
3800 \text { rpm. }\end{array}$ & $\begin{array}{l}\text { Turning was performed in wet } \\
\text { condition using inserts with } 0.2 \text {, } \\
0.4,0.8 \mathrm{~mm} \text { in nose radius where } \\
\text { feeds were } 0.05,0.1,0.2,0.3,0.4 \\
\mathrm{~mm} / \mathrm{rev} \text {, the depth of cut was } 0.5 \\
\mathrm{~mm} \text { and the speed was } 80 \\
\mathrm{~m} / \mathrm{min} \text {. }\end{array}$ & $\begin{array}{l}\text { The residual stress becomes more } \\
\text { compressive as the feed rate increases. An } \\
\text { increase of the nose radius of the insert } \\
\text { reduces the compressive residual stresses. } \\
\text { An increase of compressive residual stress } \\
\text { increases the fatigue life of turned } \\
\text { specimens. }\end{array}$ \\
\hline $\begin{array}{l}\text { (Abrāo and } \\
\text { Aspinwall 1996) } \\
\text { Axial fatigue test } \\
\text { on a 100kN } \\
\text { amsler } \\
\text { vibrophore at } \\
\text { stress ratio } 0.1 \text {. }\end{array}$ & $\begin{array}{l}\text { Dry turning was performed at } \\
\text { the speed of } 200 \mathrm{~m} / \mathrm{min} \text {, feed } \\
\text { rate of } 0.06 \mathrm{~mm} / \mathrm{rev} \text { and depth of } \\
\text { cut of } 0.5 \mathrm{~mm} \text {. } \\
\text { Cylindrical grinding was } \\
\text { performed at wheel speed of } 23 \\
\mathrm{~m} / \mathrm{s} \text {, work speed of } 8 \mathrm{~m} / \mathrm{min} \text {, } \\
\text { infeed of } 0.25 \mathrm{~mm} / \mathrm{pass} \text { and } \\
\text { transverse of } 0.13 \mathrm{~mm} / \mathrm{rev} \text { using } \\
\text { a consort alumina wheel and } \\
\text { water soluble oil coolant. }\end{array}$ & $\begin{array}{l}\text { Superior fatigue strength was obtained with } \\
\text { the turned specimens, particularly with } \\
\text { PCBN cutting tools which produced the } \\
\text { finest surface finish. }\end{array}$ \\
\hline $\begin{array}{l}\text { (Sasahara 2005) } \\
\text { Rotating bending } \\
\text { fatigue test }\end{array}$ & $\begin{array}{l}\text { Turning at feed rates of } 0.05 \text {, } \\
0.1,0.2 \text { and } 0.4 \mathrm{~mm} / \mathrm{rev} \text {, corner } \\
\text { radius of } 0.2 \text { and } 0.8 \mathrm{~mm} \text {, tool } \\
\text { edge chamfer and sharp, depth of } \\
\text { cut of } 0.2 \mathrm{~mm} \text {, cutting speed of } \\
100 \mathrm{~m} / \mathrm{min} \text {. }\end{array}$ & $\begin{array}{l}\text { Higher fatigue life to the machined } \\
\text { components can be achieved compared to } \\
\text { that of virgin materials if compressive } \\
\text { residual stresses and high hardness within } \\
\text { surface layers can be induced by the cutting } \\
\text { process. This can be obtained at a low feed } \\
\text { rate, a small corner radius and a chamfered } \\
\text { cutting edge tool. }\end{array}$ \\
\hline $\begin{array}{l}\text { (Akyildiz and } \\
\text { Livatyali 2010) } \\
\text { A four-point } \\
\text { rotary bending } \\
\text { fatigue test }\end{array}$ & $\begin{array}{l}\text { The effects of cutting speed, } \\
\text { radial feed, tool wear, and two } \\
\text { different cutting methods on the } \\
\text { fatigue strength of threaded } \\
\text { specimens were investigated for } \\
\text { thread precision and tool life. } \\
\text { The "compound straight" and } \\
\text { "compound swivelled" thread } \\
\text { cutting methods were used. }\end{array}$ & $\begin{array}{l}\text { Large variations of endurance limits of } \\
\text { threaded specimens depends on machining } \\
\text { conditions. The most significant factor is } \\
\text { tool wear and the second strongest factor is } \\
\text { cutting speed while the radial feed and } \\
\text { thread cutting method were less influential. } \\
\text { Thus, it is necessary to consider machining } \\
\text { conditions for the fatigue design of } \\
\text { precision threaded parts. }\end{array}$ \\
\hline $\begin{array}{l}\text { (Smith, Melkote } \\
\text { et al. 2007) } \\
\text { Tension-tension } \\
\text { axial fatigue tests } \\
\text { with load ratio } \\
\text { of } 0.1 \text { at } \\
300 \mathrm{MPa} \text { single } \\
\text { maximum stress }\end{array}$ & $\begin{array}{l}\text { Fatigue test specimens were (i) } \\
\text { hard turned surfaces with } \\
\text { continuous white layers, (ii) hard } \\
\text { turned surfaces with no white } \\
\text { layers, (iii) ground surfaces (G), } \\
\text { (iv) hard turned surfaces (i.e., } \\
\text { continuous white layers) with } \\
\text { super-finish, and (v) ground } \\
\text { surfaces with super-finish. The } \\
\text { cutting speed of } 122 \mathrm{~m} / \mathrm{min} \text {, feed }\end{array}$ & $\begin{array}{l}\text { Hard turned specimens exhibited at least as } \\
\text { high a fatigue life as the baseline ground } \\
\text { specimens. The white layers present on the } \\
\text { surfaces of the hard turned specimens had } \\
\text { no conclusive impact on the axial fatigue } \\
\text { performance. The superfinishing improved } \\
\text { the performance of the hard turned } \\
\text { specimens by an order of magnitude while } \\
\text { producing only marginal improvements in } \\
\text { the ground specimens. The fatigue life was }\end{array}$ \\
\hline
\end{tabular}




\begin{tabular}{|c|c|c|}
\hline $\begin{array}{l}\text { with } 8 \mathrm{~Hz} \\
\text { frequency. }\end{array}$ & $\begin{array}{l}\text { rate of } 0.127 \mathrm{~mm} / \mathrm{rev} \text {, depth of } \\
\text { cut of } 51 \text { and } 255 \mu \mathrm{m} \text {, cutting } \\
\text { edge radi of } 25 \text { and } 70 \mu \mathrm{m} \text { Hone. }\end{array}$ & $\begin{array}{l}\text { directly proportional to both the surface } \\
\text { compressive residual stress and the } \\
\text { maximum compressive residual stress in } \\
\text { the specimen. }\end{array}$ \\
\hline $\begin{array}{l}\text { (Matsumoto, } \\
\text { Hashimoto et al. } \\
\text { 1999) } \\
\text { Two fatigue tests } \\
\text { were conducted } \\
\text { using small taper } \\
\text { roller bearing } \\
\text { assemblies of a } \\
120 \text { mm outside } \\
\text { diameter for the } \\
\text { first test and } \\
\text { large taper roller } \\
\text { bearings of a } 450 \\
\text { mm outside } \\
\text { diameter for the } \\
\text { second test }\end{array}$ & $\begin{array}{l}\text { Hard turning was done using a } \\
\text { high precision CNC lathe to } \\
\text { create a bearing race profile. A } \\
\text { CBN cutting tool with a } 10 \\
\text { degree and } 0.2 \text { mm chamfer was } \\
\text { used. No tool edge honing was } \\
\text { applied. } \\
\text { The other group of bearings was } \\
\text { ground. All the race surfaces } \\
\text { were super-finished. }\end{array}$ & $\begin{array}{l}\text { Hard turned and super-finished bearings } \\
\text { had at least as long fatigue life as ground } \\
\text { and super-finished bearings. In one test, it } \\
\text { was better than ground and super-finished } \\
\text { bearings. The depth of compressive } \\
\text { residual stresses is the major difference } \\
\text { between hard turned and ground surfaces. } \\
\text { Depth of cut does not produce a significant } \\
\text { effect on residual stresses for precision hard } \\
\text { turning. The primary deformation zone has } \\
\text { a secondary effect on residual stresses. } \\
\text { Feed rate only changes residual stress near } \\
\text { the surface, but not in a deep layer. Tool } \\
\text { edge geometry is the dominant factor for } \\
\text { determining the residual stress profile. }\end{array}$ \\
\hline
\end{tabular}

\section{Other materials}

Bayomi and Abd El-Latif (Bayoumi and Abdellatif 1995) interrelated different surface roughness variables to the fatigue endurance limit of an aluminium alloy where $R a$ and $R q$ rather than spatial variable had a guiding effect on endurance limit. The influence of surface finish on the S-N curve and endurance limit is presented in Fig. 17, which shows that surface roughness has a full control on the fatigue life for machined aluminium alloy components. The samples with lower surface roughness gives higher fatigue strength at low as well as high cycle strengths. The endurance limit also reduces with the rise of surface roughness. The influence of residual stress is insignificant due to the removal of top surface of sample through polishing processes. The influence of the surface roughness hybrid parameters $D q$ (root mean square slope) and $\lambda q$ (spacing between local peaks and valleys) on fatigue endurance limit is less than that of the arithmetic mean surface finish $R a$. The shape of grooves as well as maximum height (Rt) of the surface profile are critical as the both factors inspire stress concentrations (Leverant, Langer et al. 1979) and initiates crack under fatigue conditions (Novovic, Dewes et al. 2004). Surface residual stress is often a better display of fatigue behaviour than surface features when the surface roughness, $R a$ is in range of $2.5-5 \mu \mathrm{m}$. This influence decreases with the rise of temperature because of the easing of residual stress with thermal exposure (Koster 1991). These are not due to the change of surface finish, but because of modifications of the integrity on the machined surfaces owing to the machining operation (Koster and Field 1973). 

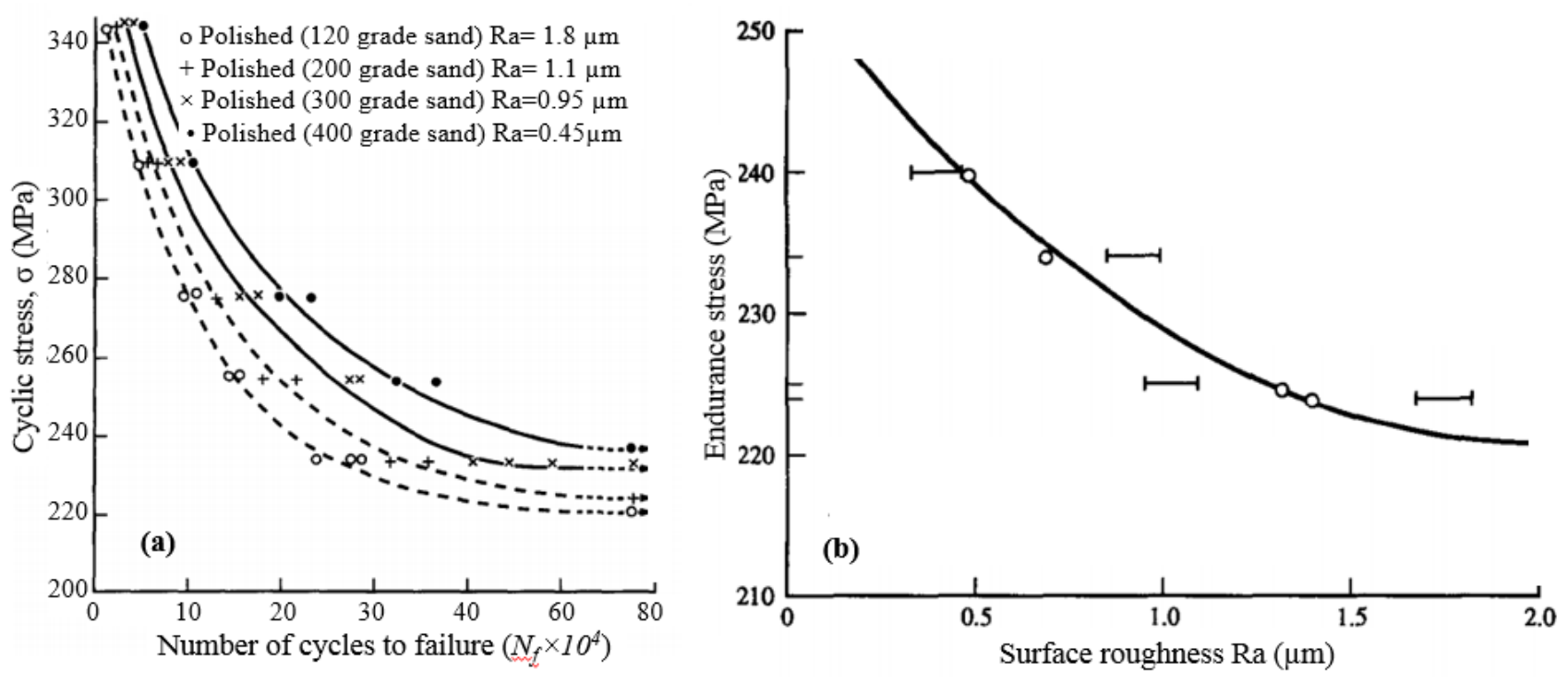

Fig. 17. Influence of surface roughness on (a) S-N curves and (b) endurance limit for aluminium alloys (Bayoumi and Abdellatif 1995)

Non-traditional machining methods influence workpiece surface integrity in different ways, and hence the fatigue behaviour, subjected to the mechanism material removal (Pramanik, Basak et al. 2015). Fig.18 presents the influence of different non-conventional machining on S-N curves for Inconel 718(Fordham, Pilkington et al. 1997). In the EDM process, the machined surface is often described by a heat affected zone with an upper hard, brittle and recast layers containing cracks and micro-cracks located normal to the machined surface. The machined surfaces also contain tensile residual stresses due to the thermal shrinkage on the subsurfaces. Worse fatigue behaviour is achieved from the combination of these facts (Trail and Bowen 1995, Fordham, Pilkington et al. 1997, Griffiths 2001). An identical circumstance is frequently noted from laser-beam machining (LBM), where thermal shrinkage of machined subsurfaces owing to the rapid solidification also incorporates unwanted tensile residual stresses (Novovic, Dewes et al. 2004).

Abrasive water-jet machining (AWJM) mainly depends on the non-thermal mechanism of material removal, which occurs through the impacts of discrete grits suspended inside the fluid. Hence the method usually introduces compressive residual stresses on the machined surfaces, which contributes to better fatigue behaviour. Unfortunately, the machined surfaces frequently contain embedded grits (Fordham, Pilkington et al. 1997, Hirano, Enomoto et al. 1997), usually with the diameter of 10-50 $\mu \mathrm{m}$, which, if combined with a lower surface finish, may give rise to stress concentration and considerably worsened fatigue performance (Fordham, Pilkington et al. 1997). 


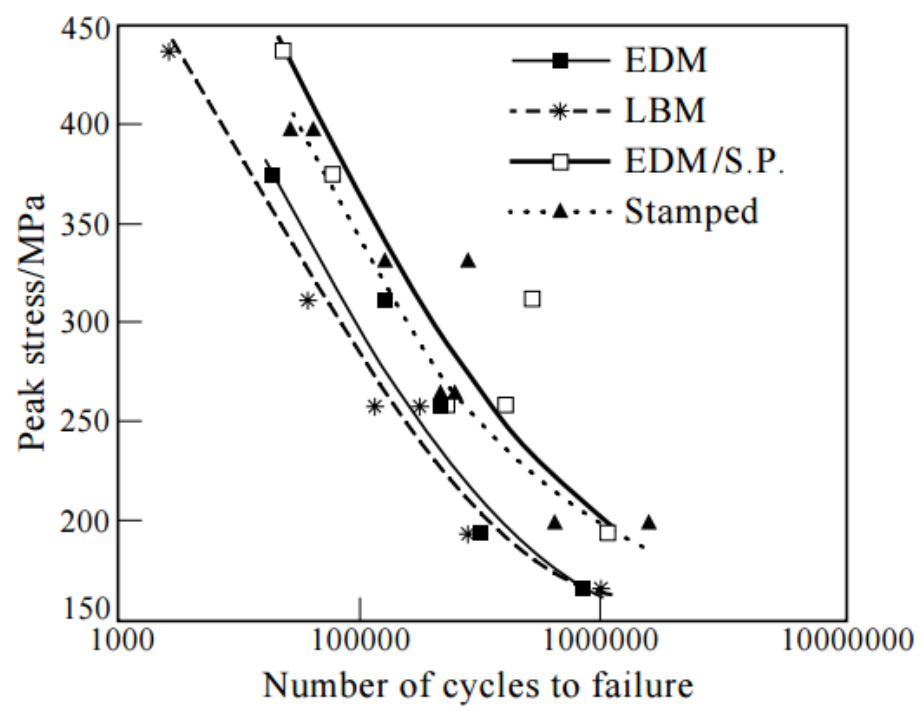

Fig.18 S-N curves for Inconel 718 membranes: stamped, LBM, EDM and EDM-SP (Fordham, Pilkington et al. 1997)

\section{Summary}

The research on the influence of machining on fatigue behaviour is still at early stage. The fatigue strength of the machined components depends on the workpiece material and, machining type and conditions. So far, the information in this research area is available only for very few alloys such as titanium, steel, aluminium and nickel alloys. Based on our holistic review, the following key points can be summarised from the above investigations:

(a) There is no clear trend on the effect of feed rate and speed on the fatigue strength of turned titanium alloys. The polishing process improves the surface roughness, but removes the surface layers with compressive residual stresses. This decreases the fatigue strength of polished specimens accordingly.

(b) The effect of residual stresses on the machined surfaces is more pronounced than that of surface roughness. The compressive residual stresses improve the fatigue strength and tensile stress reduces the fatigue strength by facilitating the crack growth.

(c) Grinding process induces tensile residual stresses on the machined surfaces due to the generation of high temperature. But milling process yields compressive residual stresses on the machined surfaces though surface roughness is worse in this case. Thus, higher fatigue strength is achieved on the workpieces produced by the milling process.

(d) Fatigue failure of titanium alloys is primarily due to the brittle fracture, in which the fracture surfaces show inter-lamellar, intra-lamellar and trans-lamellar fracture formations. 
(e) Electrical discharge machining (EDM) reduces the fatigue strength of titanium alloys due to the high population of micro-cracks and the presence of tensile residual stresses in recast layers. However, the electro-polishing improves the fatigue life by removing the recast layers.

(f) Phase change is very common during the machining of steel, which contributes to the formation of residual stresses on the machined surfaces. Due to the turning process, compressive residual stresses in the axial and hoop directions are noted when there are continuous white layers, which contributes to volume expansion due to the phase transformation on the surfaces of the workpieces. Surface layers consisting of intermittent white layers may undergo tensile or compressive stresses depending on the amounts of present white layers.

(g) The decrease in the feed allows the surface residual stress to shift towards compression residual stresses in both longitudinal and axial directions for steel. Higher compressive residual stresses cause higher fatigue life and the effect of residual stresses on fatigue life outperforms that of surface roughness. An increase of the nose radius of the insert causes a decrease in compressive residual stress. An increase in cutting speed increases the local temperature near the cutting tip, thus resulting in surface tensile stresses. If this temperature is high enough, the martensite transformation may occur in quenching by generating compressive residual stresses. High compressive residual stresses and high surface hardness are necessary to benefit a longer fatigue life. Smaller corner radius tool with chamfer increases surface hardness, which means the plastic deformation within the machined surface layer becomes more pronounced.

(h) Steel surfaces generated from grinding have weaker fatigue performance when compared to that of turning and milling for the similar reasons as noted for titanium alloys.

(i) Non-conventional machining such as EDM and laser machining generates a network of microcracks in addition to tensile residual stresses on the surfaces of all the materials. This network of cracks changes substantially whatever the level of applied stresses. The cracks initiate and propagate, and form a continuous network, leading to the premature failure of the specimens prepared by the EDM, as opposed to those prepared by traditional machining processes with better surface integrity and lower roughness.

Water jet machining produces compressive residual stresses on the Inconel 718 machined surfaces. However, the machined surfaces often contain embedded grits that can act as stress concentration sites to significantly degrade fatigue performance if combined with a high workpiece surface roughness. 


\section{References}

Abhang, L. B., Hameedullah, M. (2010). "Chip-tool interface temperature prediction model for turning process." International Journal of Engineering Science Technology 2( 4): 382-393.

Abrāo, A. M. and D. K. Aspinwall (1996). "The surface integrity of turned and ground hardened bearing steel." Wear196(1): 279-284.

Abrāo, A. M. and D. K. Aspinwall (1996). "The surface integrity of turned and ground hardened bearing steel." Wear196(1-2): 279-284.

Akyildiz, H. K. and H. Livatyali (2010). "Effects of machining parameters on fatigue behavior of machined threaded test specimens." Materials \& Design31(2): 1015-1022.

Arola, D. and C. L. Williams (2002). "Estimating the fatigue stress concentration factor of machined surfaces." International Journal of Fatigue24(9): 923-930.

Aspinwall, D., S. Soo, A. Berrisford and G. Walder (2008). "Workpiece surface roughness and integrity after WEDM of Ti-6Al-4V and Inconel 718 using minimum damage generator technology." CIRP Annals-Manufacturing Technology57(1): 187-190.

Bayoumi, M. R. and A. Abdellatif (1995). "Effect of surface finish on fatigue strength." Engineering Fracture Mechanics51(5): 861-870.

Bentley, S., A. Mantle and D. Aspinwall (1999). "The effect of machining on the fatigue strength of a gamma titanium aluminide intertmetallic alloy." Intermetallics7(8): 967-969.

Bouzid Saï, W., N. Ben Salah and J. L. Lebrun (2001). "Influence of machining by finishing milling on surface characteristics." International Journal of Machine Tools and Manufacture41(3): 443-450.

Campbell, J., K. V. Rao and R. Ritchie (1997). "On the role of microstructure in fatigue-crack growth of $\gamma$-based titanium aluminides." Materials Science and Engineering: A239: 722-728.

Dahlman, P., F. Gunnberg and M. Jacobson (2004). "The influence of rake angle, cutting feed and cutting depth on residual stresses in hard turning." Journal of Materials Processing Technology147(2): 181-184.

Dieter, G. E. (2015). "Mechanical metallurgy."

Fetullazade, E., H. K. Akyildiz and S. Saritas (2010). "Effects of the machining conditions on the strain hardening and the residual stresses at the roots of screw threads." Materials \& Design31(4): 2025-2031. Field, M. (1971). "Review of surface integrity of machined components." Ann CIRP20(2): 153-163.

Field, M., J. F. Kahles and J. Cammett (1972). "Review of measuring methods for surface integrity." CIRP21(2): 219-238. 
Fordham, J., R. Pilkington and C. Tang (1997). "The effect of different profiling techniques on the fatigue performance of metallic membranes of AISI 301 and Inconel 718." International journal of fatigue19(6): 487-502.

García Navas, V., O. Gonzalo and I. Bengoetxea (2012). "Effect of cutting parameters in the surface residual stresses generated by turning in AISI 4340 steel." International Journal of Machine Tools and Manufacture61(0): 48-57.

Ghanem, F., C. Braham and H. Sidhom (2003). "Influence of steel type on electrical discharge machined surface integrity." Journal of Materials Processing Technology142(1): 163-173.

Ghanem, F., H. Sidhom, C. Braham and M. E. Fitzpatrick (2002). "Effect of near-surface residual stress and microstructure modification from machining on the fatigue endurance of a tool steel." Journal of Materials Engineering and Performance11(6): 631-639.

Golden, P. J., R. John and W. J. Porter Iii (2010). Investigation of variability in fatigue crack nucleation and propagation in alpha+beta Ti-6Al-4V. Procedia Engineering.

Griffiths, B. (1987). "Mechanisms of white layer generation with reference to machining and deformation processes." Journal of Tribology109(3): 525-530.

Griffiths, B. (2001). Manufacturing surface technology: surface integrity and functional performance, Elsevier.

Guo, Y. B. and D. W. Yen (2004). "Hard turning versus grinding - the effect of process-induced residual stress on rolling contact." Wear256(3-4): 393-399.

Hasçalık, A. and U. Çaydaş (2007). "Electrical discharge machining of titanium alloy (Ti-6Al-4V)." Applied Surface Science253(22): 9007-9016.

Hashimoto, F., Y. B. Guo and A. W. Warren (2006). "Surface Integrity Difference between Hard Turned and Ground Surfaces and Its Impact on Fatigue Life." CIRP Annals - Manufacturing Technology55(1): 81-84.

Hirano, K., K. Enomoto, E. Hayashi and K. Kurosawa (1997). "Effects of water jet peening on corrosion resistance and fatigue strength of type 304 stainless steel." International Journal of Fatigue 10(19): 734.

Janeček, M., F. Nový, J. Stráský, P. Harcuba and L. Wagner (2011). "Fatigue endurance of Ti-6Al-4V alloy with electro-eroded surface for improved bone in-growth." Journal of the mechanical behavior of biomedical materials4(3): 417-422.

Javidi, A., U. Rieger and W. Eichlseder (2008). "The effect of machining on the surface integrity and fatigue life." International Journal of fatigue30(10): 2050-2055. 
Jha, S. K., C. J. Szczepanski, P. J. Golden, W. J. Porter and R. John (2012). "Characterization of fatigue crack-initiation facets in relation to lifetime variability in Ti-6Al-4V." International Journal of Fatigue42: 248-257.

Kahles, J. and M. Field (1967). Paper 4: Surface Integrity-A New Requirement for Surfaces Generated by Material-Removal Methods. Proceedings of the Institution of Mechanical Engineers, Conference Proceedings, SAGE Publications.

Klocke, F., D. Welling and J. Dieckmann (2011). "Comparison of grinding and Wire EDM concerning fatigue strength and surface integrity of machined Ti6Al4V components." Procedia engineering19: 184-189.

Koster, W. (1991). Effect of residual stress on fatigue of structural alloys. Practical Applications of Residual Stress Technology, Conference Proceedings, Indianapolis, Indiana.

Koster, W. and M. Field (1973). Effect of Machining Variables on the Surface and Structural Integrity of Ti. Proceedings of the North American Metalworking Research Conference.

Koster, W. and M. Field (2001). Effects of Machining Variables on the Surface and Structural metals. Proceedings of the North American Manufacturing Research Conference, SME.

Leinenbach, C. and D. Eifler (2006). "Fatigue and cyclic deformation behaviour of surface-modified titanium alloys in simulated physiological media." Biomaterials27(8): 1200-1208.

Leverant, G., B. Langer, A. Yuen and S. Hopkins (1979). "Surface residual stresses, surface topography and the fatigue behavior of Ti-6AI-4V." Metallurgical Transactions A10(2): 251-257.

M’Saoubi, R., J. C. Outeiro, B. Changeux, J. L. Lebrun and A. Morão Dias (1999). "Residual stress analysis in orthogonal machining of standard and resulfurized AISI 316L steels." Journal of Materials Processing Technology96(1-3): 225-233.

Mamalis, A. G., G. C. Vosniakos, and N. M. Vaxevanidis (1987). "'On the surface integrity of mechanically and thermally worked metal plates." " Advanced Technology of Plasticity 1: 407-414.

Mantle, A. and D. Aspinwall (1997). "Surface integrity and fatigue life of turned gamma titanium aluminide." Journal of materials processing technology72(3): 413-420.

Matsumoto, Y., M. M. Barash and C. R. Liu (1986). "Effect of Hardness on the Surface Integrity of AISI 4340 Steel." Journal of Manufacturing Science and Engineering108(3): 169-175.

Matsumoto, Y., F. Hashimoto and G. Lahoti (1999). "Surface Integrity Generated by Precision Hard Turning." CIRP Annals - Manufacturing Technology48(1): 59-62.

Matsumoto, Y., D. Magda, D. W. Hoeppner and T. Y. Kim (1991). "Effect of Machining Processes on the Fatigue Strength of Hardened AISI 4340 Steel." Journal of Manufacturing Science and Engineering113(2): 154-159. 
Mower, T. M. (2014). "Degradation of titanium 6Al-4V fatigue strength due to electrical discharge machining." International Journal of Fatigue64: 84-96.

Mueller, J., H. Rack and L. Wagner (2007). "Effects of supra-and sub-transus heat treatments on fatigue performance of Ti-6Al-4V, Ti-2007." Sci. Technol.: 383-386.

Murali, M. S. and S.-H. Yeo (2005). "Process simulation and residual stress estimation of microelectrodischarge machining using finite element method." Japanese journal of applied physics44(7R): 5254.

Newman, J., E. Phillips, M. Swain and R. Everett (1992). Fatigue mechanics: an assessment of a unified approach to life prediction. Advances in fatigue lifetime predictive techniques, ASTM International.

Nicholas, T. (2006). High cycle fatigue: a mechanics of materials perspective, Elsevier.

Novovic, D., R. Dewes, D. Aspinwall, W. Voice and P. Bowen (2004). "The effect of machined topography and integrity on fatigue life." International Journal of Machine Tools and Manufacture44(2): 125-134.

Outeiro, J. C., A. M. Dias and J. L. Lebrun (2004). "Experimental Assessment of Temperature Distribution in Three-Dimensional Cutting Process." Machining Science and Technology8(3): 357376.

Pramanik, A. (2016). "Electrical discharge machining of MMCs reinforced with very small particles." Materials and Manufacturing Processes31(4): 397-404.

Pramanik, A., A. Basak and M. N. Islam (2015). "Effect of reinforced particle size on wire EDM of MMCs." International Journal of Machining and Machinability of Materials17(2): 139-149.

Pramanik, A., A. Basak, M. N. Islam and G. Littlefair (2015). "Electrical discharge machining of 6061 aluminium alloy." Transactions of Nonferrous Metals Society of China25(9): 2866-2874.

Pramanik, A. and G. Littlefair (2014). "Developments in machining of stacked materials made of CFRP and titanium/aluminum alloys." Machining Science and Technology18(4): 485-508.

Pramanik, A. and G. Littlefair (2015). "Machining of titanium alloy (Ti-6Al-4V) — theory to application." Machining Science and Technology19(1): 1-49.

Pramanik, A. and G. Littlefair (2015). "Wire EDM Mechanism of MMCs with the Variation of Reinforced Particle Size." Materials and Manufacturing Processes(just-accepted).

Pramanik, A., L. C. Zhang and Y. Q. Chen (2010). Efficient Machining of Artificial Hip Joint Components. Advanced Materials Research, Trans Tech Publ.

Rech, J. and A. Moisan (2003). "Surface integrity in finish hard turning of case-hardened steels." International Journal of Machine Tools and Manufacture43(5): 543-550. 
Sasahara, H. (2005). "The effect on fatigue life of residual stress and surface hardness resulting from different cutting conditions of $0.45 \% \mathrm{C}$ steel." International Journal of Machine Tools and Manufacture45(2): 131-136.

Sasahara, H., T. Obikawa and T. Shirakashi (2004). "Prediction model of surface residual stress within a machined surface by combining two orthogonal plane models." International Journal of Machine Tools and Manufacture44(7-8): 815-822.

Schwach, D. W. and Y. B. Guo (2006). "A fundamental study on the impact of surface integrity by hard turning on rolling contact fatigue." International Journal of Fatigue28(12): 1838-1844.

Sharman, A., D. Aspinwall, R. Dewes, D. Clifton and P. Bowen (2001). "The effects of machined workpiece surface integrity on the fatigue life of $\gamma$-titanium aluminide." International Journal of Machine Tools and Manufacture41(11): 1681-1685.

Siebel, E. (1957). "Influence of surface roughness on the fatigue strength of steels and non-ferrous alloys." Engineers Digest18: 109-112.

Smith, S., S. N. Melkote, E. Lara-Curzio, T. R. Watkins, L. Allard and L. Riester (2007). "Effect of surface integrity of hard turned AISI 52100 steel on fatigue performance." Materials Science and Engineering: A459(1): 337-346.

Stefanescu, D., C. Truman, D. Smith and P. Whitehead (2006). "Improvements in residual stress measurement by the incremental centre hole drilling technique." Experimental mechanics46(4): 417427.

Stráský, J., M. Janeček, P. Harcuba, M. Bukovina and L. Wagner (2011). "The effect of microstructure on fatigue performance of $\mathrm{Ti}-6 \mathrm{Al}-4 \mathrm{~V}$ alloy after EDM surface treatment for application in orthopaedics." Journal of the mechanical behavior of biomedical materials4(8): 1955-1962.

Suhr, R. (1988). "High Cycle Fatigue(in High Temperature Materials)." The Institute of Metals, Mechanical Testing: 226-287.

Suresh, S. (1998). Fatigue of materials, Cambridge university press.

Taylor, D. and O. Clancy (1991). "The fatigue performance of machined surfaces." Fatigue \& Fracture of Engineering Materials \& Structures14(2-3): 329-336.

Thiele, J. D., S. N. Melkote, R. A. Peascoe and T. R. Watkins (1999). "Effect of Cutting-Edge Geometry and Workpiece Hardness on Surface Residual Stresses in Finish Hard Turning of AISI 52100 Steel." Journal of Manufacturing Science and Engineering122(4): 642-649.

Trail, S. and P. Bowen (1995). "Effects of stress concentrations on the fatigue life of a gamma-based titanium aluminide." Materials Science and Engineering: A192: 427-434. 
Xie, Q., A. E. Bayoumi, L. A. Kendall and G. L. Sheldon (1989). A study on residual stresses and tool wear induced by machining processes. Proceedings North American Manufacturing Research Conference XVII.

Yu, J. W., P. Xiao, Y. S. Liao and M. Cheng (2009). Surface Integrity in Electrical Discharge Machining of Ti-6Al-4V. Advanced Materials Research, Trans Tech Publ.

Zahavi, E., V. Torbilo and S. Press (1996). Fatigue design: life expectancy of machine parts, CRC press.

Zhang, H. (1995). Investigation of Machinability of Titanium Aluminides, University of Birmingham, School of Metallurgy and Materials.

Zhang, L. C., E. Kiat and A. Pramanik (2009). A briefing on the manufacture of hip joint prostheses. Advanced Materials Research, Trans Tech Publ.

Zlatin, N. and M. Field (1973). Procedures and precautions in machining titanium alloys. Titanium Science and Technology, Springer: 489-504. 